\title{
Clinical practice guidelines for the use of noninvasive positive-pressure ventilation and noninvasive continuous positive airway pressure in the acute care setting
}

\author{
Sean P. Keenan MD MSc, Tasnim Sinuff MD PhD, Karen E.A. Burns MD MSc, John Muscedere MD, \\ Jim Kutsogiannis MD, Sangeeta Mehta MD, Deborah J. Cook MD MSc, Najib Ayas MD, \\ Neill K.J. Adhikari MD CM MSc, Lori Hand BSc RRT, Damon C. Scales MD PhD, Rose Pagnotta RRT, \\ Lynda Lazosky RRT, Graeme Rocker MD, Sandra Dial MD, Kevin Laupland MD MSc, Kevin Sanders MD, \\ Peter Dodek MD MHSc, as the Canadian Critical Care Trials Group / Canadian Critical Care Society \\ Noninvasive Ventilation Guidelines Group
}

An abridged version of this article appeared in the February 22, 2011 issue of $C M A J$

See related commentary by Bersten, page 293

$\mathrm{O}$ ver the past two decades, the use of noninvasive positive-pressure ventilation and noninvasive continuous positive airway pressure by mask has increased substantially for acutely ill patients. Initial case series and uncontrolled cohort studies that suggested benefit in selected patients ${ }^{1-13}$ led to many randomized controlled trials (RCTs). ${ }^{14-151}$ Both methods of ventilation have been used in the setting of acute respiratory failure to avoid endotracheal intubation in different patient populations and settings, with variable success. ${ }^{14-69,117-123,134-141}$ In addition, noninvasive positive-pressure ventilation has been used to facilitate early liberation from conventional mechanical ventilation $^{72-82}$ and to prevent reintubation. ${ }^{70,71,83-87}$

These guidelines were developed to answer the following questions: What evidence is available in the literature to support recommendations for the use of noninvasive positive-pressure ventilation and continuous positive airway pressure for patients who are at risk of or who have acute respiratory distress or failure, patients who have undergone surgery and patients who are being weaned from mechanical ventilation or have recently undergone extubation? In addition, how can these two modes of noninvasive ventilation be optimally applied in these settings?

Consensus conference statements ${ }^{152,153}$ and guidelines ${ }^{154-157}$ exist for the use of noninvasive ventiliation (the term used throughout this paper to refer to both noninvasive positive-pressure ventilation and continuous positive airway pressure) in the acute care setting. However, since publication of the two English guidelines addressing use in the acute care setting, ${ }^{154,156}$ many new RCTs have been published. In addi- tion, the first ${ }^{154}$ of the two previous guidelines predated the development of the Grading of Recommendations Assessment, Development and Evaluation (GRADE) Working Group methodology, ${ }^{158-160}$ and a less rigorous methodology was used in the second. ${ }^{156}$ Accordingly, we conducted a comprehensive search and appraisal of the current literature, using the GRADE methodology to assess the quality of the research and to generate clinical recommendations.

\section{Methods}

\section{Leadership and scope}

An 18-member guidelines panel of universityaffiliated clinicians, led by two cochairs, was formed in June 2007 as an initiative of the Canadian Critical Care Trials Group / Canadian Critical Care Society Noninvasive Ventilation Guidelines Group. The panel consisted of 15 physicians and 3 respiratory therapists who had a variety of

\section{KEY POINTS}

- Noninvasive positive-pressure ventilation should be the first option for ventilatory support for patients with either a severe exacerbation of chronic obstructive pulmonary disease (COPD) or cardiogenic pulmonary edema.

- Continuous positive airway pressure delivered by mask appears to be just as effective as noninvasive positive-pressure ventilation for patients with cardiogenic pulmonary edema.

- Patients with acute respiratory distress or hypoxemia, either in the postoperative setting or in the presence of immunosuppression, can be considered for a trial of noninvasive positive-pressure ventilation.

- Patients with COPD can be considered for a trial of early extubation to noninvasive positive-pressure ventilation in centres with extensive experience in the use of noninvasive positive-pressure ventilation. 
backgrounds in clinical and/or nonclinical expertise: 15 were experts in critical care medicine, 12 in pulmonary medicine, 5 in noninvasive positive-pressure ventilation, 15 in clinical research methodology and 5 in guideline development.

The target audience for these guidelines is clinicians who use either form of noninvasive ventilation for acutely ill patients. The referent setting was the Canadian health care system.

\section{Data sources}

We searched the following electronic databases from their inception to June 2009: MEDLINE, EMBASE, CINAHL, CENTRAL (the Cochrane Central Register of Controlled Trials), DARE (the Database of Abstracts of Reviews of Effectiveness), the Cochrane Database of Systematic Reviews, ACP Journal Club database, the metaRegister of Controlled Trials, ClinicalTrials .gov and the Journals@ Ovid database. For the search strategies, see Appendix 1 (available at www.cmaj.ca/cgis/content/full/cmaj.100071/DC1). We also searched personal files and the bibliographies of relevant articles.

\section{Selection criteria}

We identified RCTs that included adults admitted to acute care hospitals who were at risk of or who had acute respiratory failure. We included studies involving patients with acute or acute-onchronic respiratory failure. In clinical terms, there is a continuum from respiratory distress, marked by increased work of breathing (where an increase in the respiratory rate reflects the increase in work of breathing), to respiratory failure, for which immediate endotracheal intubation is required. Various definitions of respiratory failure have been used conventionally for years, but they are somewhat arbitrary and not always useful for the clinician. Some patients who are in clear respiratory extremis may not meet the blood gas criteria for respiratory failure. Conversely, other patients have respiratory failure as defined by clinical criteria but do not need urgent ventilation. Clearly, there is a spectrum of severity of respiratory compromise that, in general, is worse with increasing respiratory rate and signs of increased work of breathing. Some studies, but not others, have specified strict blood gas criteria for respiratory distress and failure. Rather than defining respiratory failure a priori, we included trials that used either clinical or arterial blood gas criteria, as well as studies in which patients were in respiratory distress according to clinical criteria and were believed to be at risk of requiring ventilatory support in the future.

We excluded studies of noninvasive ventila- tion for patients with chronic respiratory failure in an outpatient setting. Each included trial directly compared the two types of noninvasive ventilation with standard therapy or with each other and reported physiologic outcomes (e.g., arterial blood gases, vital signs) and/or clinical outcomes (e.g., endotracheal intubation, hospital mortality). We included only parallel-design RCTs. We excluded studies with crossover design because inferences about clinical outcomes are limited in these trials. We also excluded pseudorandomized trials (such as those in which patients were assigned to study group by alternate assignment or hospital registry number) and abstract publications.

No language restrictions were applied; nonEnglish publications were professionally translated into English.

The panel cochairs independently reviewed all study abstracts and selected potentially relevant trials for further review. Disagreements on inclusion of articles were resolved through consensus between the two cochairs.

\section{Quality assessment and data abstraction}

Of the 18 members of the guideline panel, 16 participated in the review of RCTs, working in eight pairs. Working independently, each member of each pair of reviewers critically appraised assigned RCTs using a tool developed by the panel specifically for this project. For each RCT, each member of the pair of reviewers independ ently abstracted data regarding trial validity, and the two reviewers in each pair achieved consensus on the validity and results of assigned RCTs.

The following data were abstracted to determine validity: concealment of allocation, selection of patients, similarity of groups at baseline, treatment protocol, co-interventions, definitions of outcomes, extent of follow-up, adherence to the intention-to-treat principle, patient population, hospital location, number of sites and strategies for the initial application and titration of noninvasive ventilation. All reported outcomes were recorded.

We conducted meta-analyses for topics for which at least two RCTs were identified. For each population and intervention (noninvasive positive-pressure ventilation, continuous positive airway pressure by mask), we used relative risk (RR) as the summary estimate of effect for dichotomous outcomes and weighted mean difference for continuous outcomes. We used a random-effects model.

\section{Development of recommendations}

All members were given literature describing the GRADE methodology to help generate a summary statement for each guideline topic. ${ }^{158-160}$ In 
addition, a GRADE expert reviewed this methodology with the panel members on two occasions before the start of the deliberation process. The panel met in person three times and communicated frequently by email. Before each meeting, summaries of the pooled results (based on meta-analyses) and evidence tables were sent to the panel members for review.

At the first meeting, the guideline panel agreed to use endotracheal intubation and hospital mortality as the primary outcomes of interest. We used length of the hospital stay if endotracheal intubation and mortality were either unavailable in the original publications or not significantly different between groups. For trials that assessed different modes of ventilation or interfaces (i.e., types of masks), we also used measures of patient tolerance as an outcome of interest.

The outcome of "treatment failure," defined by trial-specific physiologic and gas exchange criteria, was reported in a number of recent trials. Many of these trials allowed crossover of patients from the standard therapy arm to either noninvasive positive-pressure ventilation or continuous positive airway pressure, which potentially confounds the outcomes of endotracheal intubation and hospital mortality. For clinical topics where this approach was used in either a large proportion of trials or in a few trials accounting for a large proportion of patients, we also considered treatment failure as an outcome of interest. In pooling results for treatment failure, we used rates of endotracheal intubation when specific criteria for treatment failure were not included.

The GRADE methodology initially entailed assigning to each guideline statement both a number (to summarize the strength of the statement) and a letter (to summarize the quality of the evidence). More recently, some guideline experts have preferred to include or substitute symbols and/or statements for the traditional number and letter grades. Table 1 summarizes the GRADE Working Group's definitions of these categories. ${ }^{158-160}$ Standard terms in these statements were "recommend," "suggest" or "no recommendation." For topics we considered to have sufficient quality and quantity of supporting evidence from RCTs, strong recommendations were assigned a grade of 1 and were described by the phrase "we recommend"; weaker recommendations were assigned a grade of 2 and were described by the phrase "we suggest." For topics that lacked sufficient evidence, we made no recommendation. In these situations, we stated that noninvasive positivepressure ventilation or continuous positive airway pressure could be considered but that there was a lack of literature to support either intervention because published RCTs were inconclusive (denoted by the term "lack of sufficient evidence") or because no RCTs had been published (denoted by "lack of RCTs").

We used GRADEprofiler (GRADEpro) software, version 3.2 (available through Cochrane IMS) to generate evidence tables from which panel members developed the final guideline statements. The GRADEpro software generated letter grades, which incorporated limitations of study design, inconsistency, indirectness, imprecision and publication bias, to assess the quality of evidence as high, moderate, low or very low. The panel then systematically evaluated these quality criteria. The panel also incorporated semiquantitative assessments of safety (estimated probability of avoiding significant harm that may be associated with the intervention), feasibility (ease of implementation of the intervention) and cost (estimated cost of implementing the intervention) into the GRADEpro document for each topic. We did not include direct assessments of patient values and preferences. Our underlying values and preferences were to ensure that any recommended use of these technologies was safe, effective, affordable and feasible within the Canadian health care system.

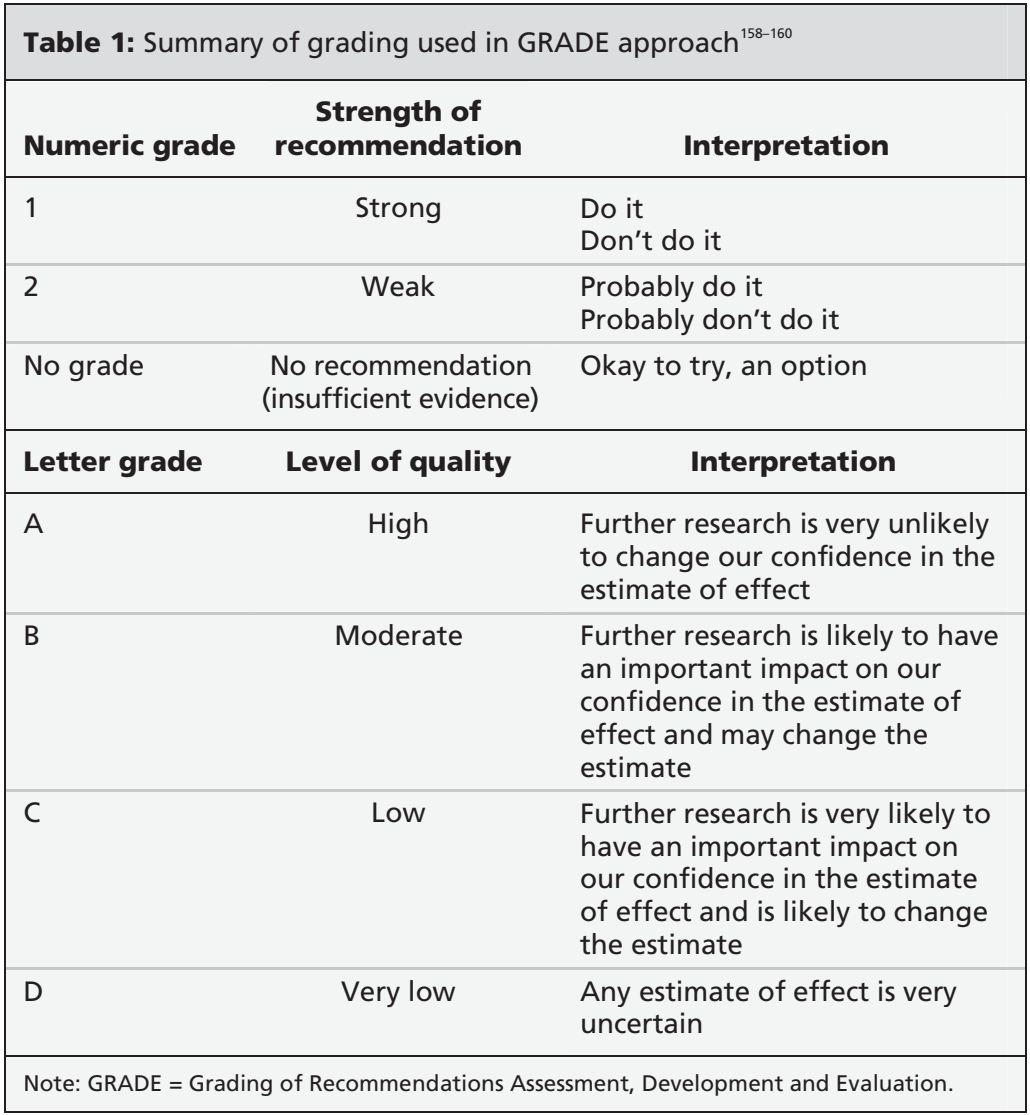


After each panel meeting, the cochairs compiled the summaries and recommendations, and the panel members reviewed this material for clarity and accuracy. To assess the degree of agreement of each panel member with the final guideline statements, all members independently rated their agreement with each statement using a Likert-type scale from 1 to 9 , anchored by "disagree completely" at the low end and "agree completely" at the high end.

The panel members prepared background documents for the topics they reviewed, and the cochairs compiled these documents into the results section of this guideline document. We formatted the full guideline document to include a summary of the evidence and a statement for each topic. We also developed a summary of the guideline statements as a quick reference guide.

A draft of the guideline document was submitted to the executive of the Canadian Critical Care Society and for internal review by three reviewers of the Canadian Critical Care Trials Group. Both groups reviewed the guidelines and endorsed the final version. In addition, an international expert on noninvasive ventilation reviewed the final guidelines. All reviewers were asked to assess the logic, clarity and practicality of the guideline. The cochairs revised the document on the basis of feedback received. As an additional assessment of the comprehensiveness of these guidelines, and to be as transparent as possible about its potential deficiencies, we evaluated the final guideline using the AGREE (Appraisal of Guidelines Research and Evaluation) instrument. ${ }^{161}$

\section{Funding}

Funding for this work was provided by a grant from the Canadian Institutes of Health Research and an unrestricted grant from Philips/Respironics Inc., Murrysville, Pennsylvania. The funding sources played no role in selection of studies, interpretation of the appraisals, or development, review or approval of the guidelines.

\section{Clinical recommendations}

The literature search, beginning with a general overview of the literature and then focusing on the RCTs, is summarized in Figure 1. In total, we identified 3033 studies and included 146 RCTs in our review. We report here the final summary statements and their grades for use of noninvasive positive-pressure ventilation or continuous positive airway pressure by mask in acutely ill patients in the following three clinical settings: acute respiratory failure, management after intub ation, and the postoperative setting. We also report recommendations on technical strategies to optimize the use of noninvasive ventilation (e.g., interfaces, mode). See Table 2 for a summary of the statements. The abridged version of this article (available at www.cmaj.ca) includes a table organized by the strength and quality of the recommendations. The degree of agreement among members of the consensus panel was high (see Appendix 2, available at www.cmaj.ca/cgis /content/full/cmaj.100071/DC1), which added some validity to the final statements.

\section{Acute respiratory failure}

\section{Exacerbation of COPD}

\section{Noninvasive positive-pressure ventilation versus standard therapy}

We identified 16 published RCTs ${ }^{14-24,26,28-31}$ comparing noninvasive positive-pressure ventilation plus standard therapy with standard therapy alone for patients with exacerbation of COPD, 14 of which reported endotracheal intubation and hospital mortality. We excluded two trials in which patients who experienced respiratory failure were not offered endotracheal intubation. ${ }^{14,17}$ The included trials had lower incidence of endotracheal intubation (RR 0.39, 95\% confidence interval $[\mathrm{CI}] 0.28-0.54)$ and hospital mortality (RR 0.52, 95\% CI 0.36-0.76) among patients who received noninvasive positive-pressure ventilation. Inclusion and exclusion criteria were variable, but the majority of trials included patients with severe exacerbations, defined as initial arterial $\mathrm{pH}$ less than 7.35 (and relative hypercarbia), and a correspondingly high intubation rate in their control arms. The three RCTs involving patients with milder exacerbations did not find an important reduction in risk of endotracheal intubation (RR $0.71,95 \%$ CI 0.16-3.08) or hospital mortality (RR 1.05 , 95\% CI 0.07 6.36). ${ }^{21,29,31} \mathrm{~A}$ single RCT included a subgroup of patients with acute exacerbation of COPD in the setting of severe community-acquired pneumonia, ${ }^{38}$ whereas almost all other trials involving patients with exacerbation of COPD excluded patients with pneumonia. In that trial, ${ }^{38}$ use of noninvasive positive-pressure ventilation was associated with a reduction in endotracheal intubation $(0 / 12$ in intervention arm v. 5/12 in control arm, $p=0.005$ ).

\section{Helium-oxygen with noninvasive positive- pressure ventilation}

One RCT evaluated the use of helium-oxygen (heliox; 80:20 mixture) in addition to noninvasive positive-pressure ventilation for patients with exacerbation of COPD. ${ }^{33}$ There was no dif- 
ference in rate of endotracheal intubation $(8 / 59$ with heliox v. 13/64 for control; $p=0.33$ ) or hospital mortality ( $9 / 59$ v. $6 / 64 ; p=0.48)$.

\section{Noninvasive positive-pressure ventilation} versus conventional mechanical ventilation Two published RCTs compared noninvasive positive-pressure ventilation with intubation and conventional mechanical ventilation for patients with exacerbation of COPD severe enough to warrant immediate assisted ventilation. ${ }^{120,123}$ These patients constitute a subgroup that is often excluded from other trials designed to prevent intubation in patients with COPD, because they meet the criteria for intubation at the time of presentation. Use of noninvasive positive-pressure ventilation resulted in avoidance of intubation for the majority of patients in these two trials (34 of 61), but there was no significant difference in mortality in the intensive care unit (ICU) (RR 1.24, 95\% CI 0.45-3.41) $)^{121,124}$ or in hospital mortality. ${ }^{121}$ The generalizability of these trial results beyond specialized centres is uncertain because for all of the patients, there was a high risk that noninvasive positive-pressure ventilation would fail and they would need intubation.

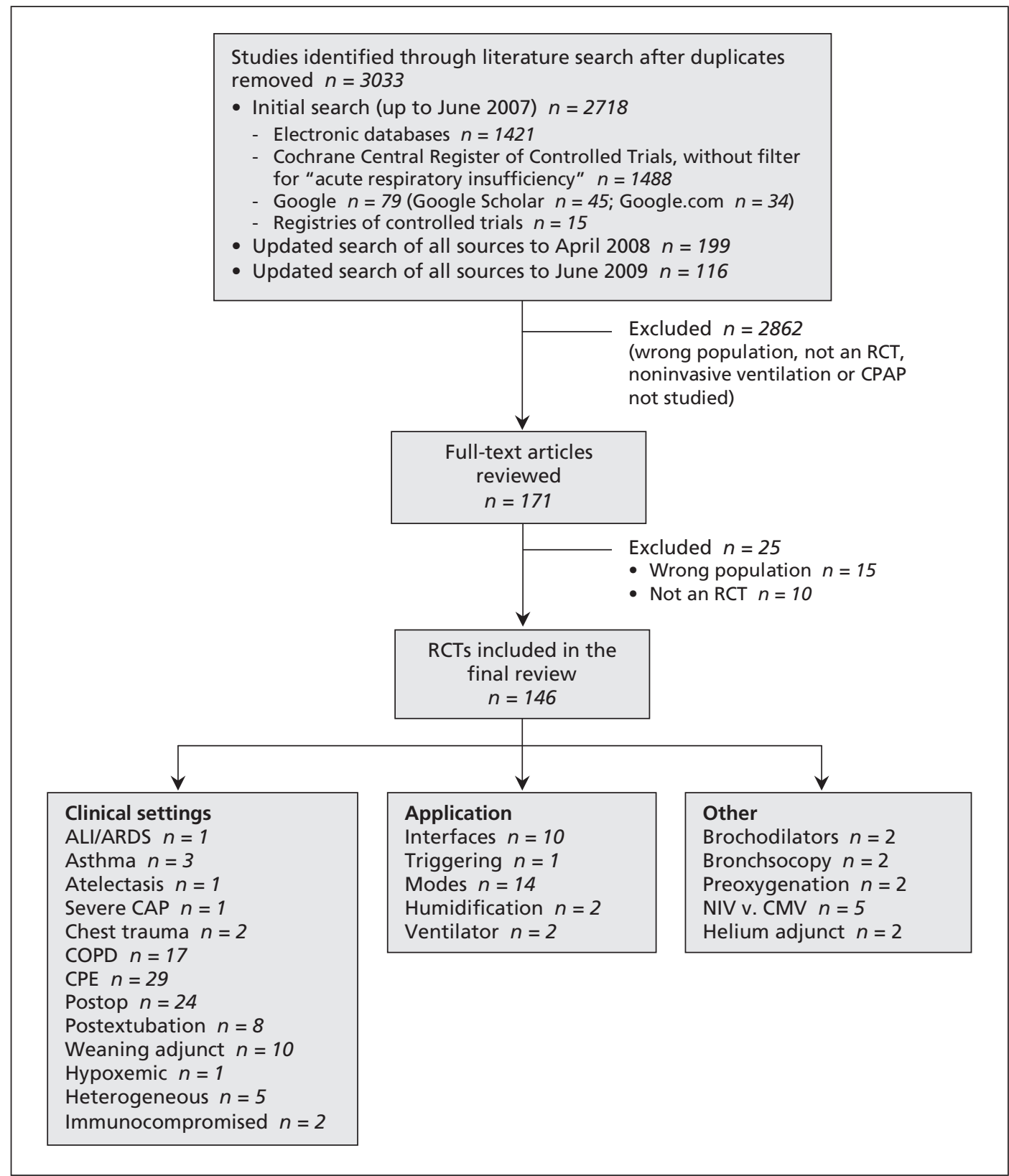

Figure 1: Summary of search results. ALI = acute lung injury, ARDS = acute respiratory distress syndrome, CAP = community-acquired pneumonia, $C M V=$ conventional mechanical ventilation, $C O P D=$ chronic obstructive pulmonary disease, $\mathrm{CPAP}=$ continuous positive airway pressure, $\mathrm{CPE}=$ cardiogenic pulmonary edema, NIV = noninvasive ventilation, $\mathrm{RCT}$ = randomized controlled trial. 
Table 2: Summary of clinical practice guideline statements for the use of noninvasive positive-pressure ventilation and noninvasive continuous positive airway pressure in the acute care setting (part 1 of 3)

Treatment

Guideline statement

Grade

Acute respiratory failure

Severe exacerbation of COPD

NPPV v. standard therapy

We recommend the use of NPPV in addition to usual care in patients who have a

CPAP v. standard therapy severe exacerbation of COPD ( $\mathrm{pH}<7.35$ and relative hypercarbia)

NPPV + heliox v. standard therapy

We make no recommendation about the use of CPAP in patients who have a severe exacerbation of COPD, because of a lack of RCTs

We suggest that helium-oxygen (heliox) not be routinely used in patients who have a severe exacerbation of COPD and who are receiving NPPV

CPAP + heliox v. standard therapy

We make no recommendation about the use of heliox with CPAP in patients who

NPPV v. conventional mechanical ventilation have a severe exacerbation of COPD, because of a lack of RCTs

We make no recommendation about the use of NPPV versus intubation and conventional mechanical ventilation in patients who have a severe exacerbation of COPD that requires ventilator support, because of insufficient evidence

CPAP v. conventional mechanical ventilation

We make no recommendation about the use of CPAP in patients who have a severe exacerbation of COPD that requires ventilator support, because of a lack of RCTs

Exacerbation of asthma

NPPV

We make no recommendation about the use of NPPV in patients who have an exacerbation of asthma, because of insufficient evidence

CPAP

We make no recommendation about the use of CPAP in patients who have an

Cardiogenic pulmonary edema

NPPV or CPAP v. standard therapy exacerbation of asthma, because of a lack of RCTs

We recommend the use of either NPPV or CPAP in patients who have cardiogenic coronary syndrome requiring acute coronary revascularization

Acute lung injury

NPPV v. standard therapy

We make no recommendation about the use of NPPV in patients who have acute lung injury, because of a lack of RCTs

CPAP v. standard therapy

We recommend that CPAP not be used in patients who have acute lung injury

Severe community-acquired

pneumonia

NPPV v. standard therapy

We make no recommendation about the use of NPPV in patients who have severe community-acquired pneumonia and no prior history of COPD, because of insufficient evidence

CPAP v. standard therapy

We make no recommendation about the use of CPAP in patients who have severe community-acquired pneumonia and no prior history of COPD, because of a lack of RCTs

Chest trauma

NPPV or CPAP (patients without respiratory distress)

We make no recommendation about the use of either NPPV or CPAP in patients

NPPV (patients with respiratory who have chest trauma without respiratory distress, because of a lack of RCTs

distress)

We make no recommendation about the use of NPPV in patients who have chest trauma and respiratory distress, because of a lack of RCTs

CPAP (patients with respiratory

We make no recommendation about the use of CPAP in patients who have chest distress) trauma and respiratory distress, because of insufficient evidence

Immunosuppression in conjunction

with acute respiratory distress or

failure

NPPV v. standard therapy

We suggest that NPPV be used in immunosuppressed patients who have acute

CPAP v. standard therapy respiratory failure

We make no recommendation about the use of CPAP in immunosuppressed 
Table 2: Summary of clinical practice guideline statements for the use of noninvasive positive-pressure ventilation and noninvasive continuous positive airway pressure in the acute care setting (part 2 of 3 )

\begin{tabular}{|l}
\hline Treatment \\
\hline Acute respiratory failure - continu \\
\hline Bronchoscopy in patients with hypoxemi \\
\hline Bronchoscopy \\
\hline After intubation \\
$\begin{array}{l}\text { Adjunct to early liberation from } \\
\text { mechanical ventilation }\end{array}$ \\
\hline $\begin{array}{l}\text { NPPV v. conventional mechanical } \\
\text { ventilation (patients with COPD) }\end{array}$ \\
\hline $\begin{array}{l}\text { NPPV v. conventional mechanical } \\
\text { ventilation (patients without COPD) }\end{array}$ \\
\hline $\begin{array}{l}\text { CPAP v. conventional mechanical } \\
\text { ventilation }\end{array}$ \\
\hline $\begin{array}{l}\text { Transition to spontaneous breathing } \\
\text { after planned extubation }\end{array}$ \\
\hline NPPV v. standard (high-risk patients)
\end{tabular}

We suggest that NPPV be used to facilitate early liberation from mechanical ventilation in patients who have COPD, but only in centres that have expertise in NPPV

We make no recommendation about the use of either NPPV or CPAP in patients evidence

We make no recommendation about the use of NPPV to facilitate early liberation from mechanical ventilation in patients who do not have COPD, because of insufficient evidence

We make no recommendation about the use of CPAP to facilitate early liberation from mechanical ventilation, because of a lack of RCTs

We suggest that NPPV be used after planned extubation in patients who are considered to be at high risk of recurrent respiratory failure, but only in centres that have expertise in NPPV

NPPV v. standard (low-risk patients)

We suggest that NPPV not be used after planned extubation in patients who are considered to be at low risk of respiratory failure

CPAP v. standard

We make no recommendation about the use of CPAP after planned extubation, because of a lack of RCTs

Treatment for acute respiratory failure after extubation

NPPV v. conventional mechanical ventilation (patients without COPD)

NPPV v. conventional mechanical ventilation (patients with COPD)
We suggest that NPPV not be routinely used in patients who do not have COPD and who have postextubation respiratory failure

We make no recommendation about the use of NPPV in patients who have COPD and postextubation respiratory failure, because of insufficient evidence

We make no recommendation about the use of CPAP in patients who have postextubation respiratory failure, because of a lack of RCTs
$2 C$

NA

NA

CPAP v. conventional mechanical ventilation

\section{Postoperative setting}

Prevention of acute respiratory failure after low-risk surgery

NPPV or CPAP (low-risk patients, low-risk surgery)

NPPV or CPAP (cardiac surgery)

We make no recommendation about the use of either NPPV or CPAP in low-risk patients after low-risk surgery to prevent respiratory failure, because of insufficient evidence

We make no recommendation about the use of NPPV to prevent respiratory

failure after cardiac surgery, because of a lack of RCTs, and we make no recommendation about the use of CPAP to prevent respiratory failure after cardiac surgery, because of insufficient evidence

NPPV or CPAP (high-risk patients, We make no recommendation about the use of either NPPV or CPAP in patients low-risk surgery) at high risk (because of associated comorbidity) to prevent respiratory failure after low-risk surgical procedures, because of insufficient evidence

Prevention of acute respiratory failure after high-risk surgery NPPV or CPAP for postoperative patients (high-risk surgery)

We make no recommendation about the use of NPPV to prevent respiratory failure after high-risk surgical procedures, because of a lack of RCTs, and we make no recommendation about the use of CPAP to prevent respiratory failure after high-risk surgical procedures, because of insufficient evidence 
Table 2: Summary of clinical practice guideline statements for the use of noninvasive positive-pressure ventilation and noninvasive continuous positive airway pressure in the acute care setting (part 3 of 3 )

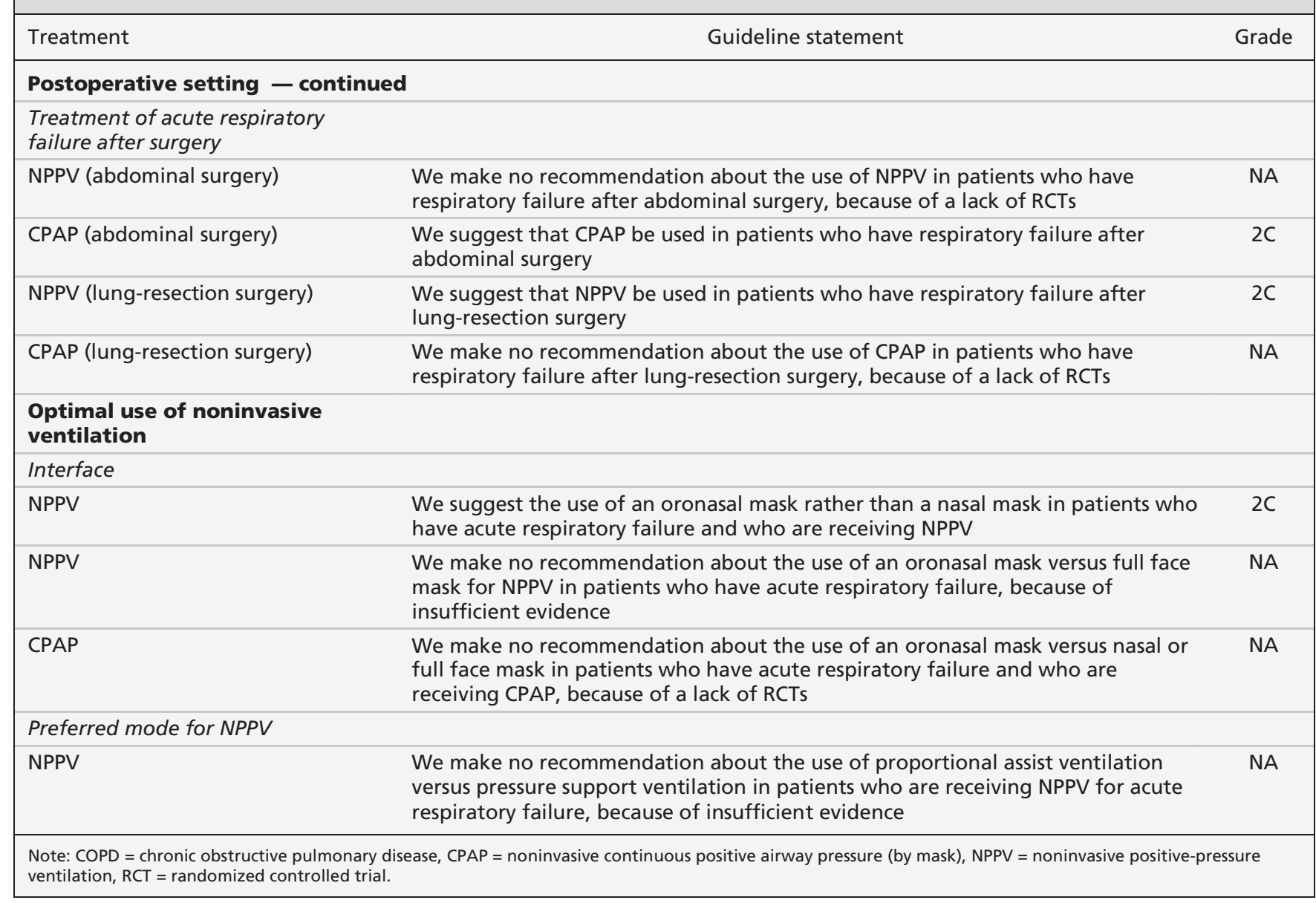

Continuous positive airway pressure for patients with exacerbation of COPD

We did not identify any RCTs investigating continuous positive airway pressure by mask for patients with COPD.

\section{Statements}

- We recommend the use of noninvasive positive-pressure ventilation in addition to usual care in patients who have a severe exacerbation of COPD $(\mathrm{pH}<7.35$ and relative hypercarbia) (grade 1A recommendation).

- We suggest that heliox not be routinely used in patients with severe exacerbation of COPD who are receiving noninvasive positive-pressure ventilation (grade $2 \mathrm{C}$ recommendation).

- We make no recommendation about the use of noninvasive positive-pressure ventilation versus intubation and conventional mechanical ventilation in patients who have a severe exacerbation of COPD that requires ventilator support, because of insufficient evidence.
- We make no recommendation about the use of continuous positive airway pressure by mask in patients who have a severe exacerbation of COPD, because of a lack of RCTs.

\section{Exacerbation of asthma}

Three small RCTs on the use of noninvasive positive-pressure ventilation in patients with exacerbation of asthma have been published. ${ }^{34-36}$ One trial, which cited selection bias in patient enrolment leading to a small sample size ( $n=$ 35 ), found no differences in outcomes. ${ }^{34}$ The second trial was a single-centre trial of 33 patients that used sham noninvasive ventilation in the control group ${ }^{35}$ None of the patients were intubated, and all survived the hospital stay. However, there was a more rapid improvement in the forced expiratory volume in the first second $\left(\mathrm{FEV}_{1}\right)$, and fewer patients required admission to hospital (3/17 v. $10 / 16 ; p=0.013)$. The sham therapy may have disadvantaged the control group by increasing the work of breathing. Finally, in a recent three-arm trial $(n=40)$ com- 
paring two pressure levels of noninvasive positive-pressure ventilation with oxygen therapy alone, a greater reduction in dyspnea and a greater increase in $\mathrm{FEV}_{1}$ were reported for the group that received noninvasive ventilation. ${ }^{36}$ Importantly, the patients in the latter two RCTs did not have severe exacerbation of asthma (none required endotracheal intubation). Overall, the quality and quantity of the evidence were low, and there were very few outcome events in any of the studies. We did not identify any RCTs on the use of continuous positive airway pressure in this population.

\section{Statements}

- We make no recommendation about the use of noninvasive positive-pressure ventilation in patients who have an exacerbation of asthma, because of insufficient evidence.

- We make no recommendation about the use of continuous positive airway pressure by mask in patients who have an exacerbation of asthma, because of a lack of RCTs.

\section{Cardiogenic pulmonary edema}

The use of noninvasive ventilation for patients with cardiogenic pulmonary edema and acute respiratory failure has been studied extensively. We identified 20 relevant RCTs. ${ }^{42-46,48-51,53-57,59,61,62,6466}$ These trials examined the use of noninvasive positive-pressure ventilation plus usual therapy versus usual therapy alone ${ }^{48,49,53}$ continuous positive airway pressure by mask plus usual therapy versus usual therapy alone,,$^{42-44,46,5,5,55,66}$ continuous positive airway pressure by mask plus usual therapy versus noninvasive positive-pressure ventilation plus usual therapy ${ }^{45,54,57,59,61,62}$ or all three of these treatments. ${ }^{50,56,64,65}$ Before publication of a recent large RCT, ${ }^{65}$ which accounted for $40 \%$ of all patients who have been studied in RCTs of continuous positive airway pressure for cardiogenic pulmonary edema and $70 \%$ of patients receiving noninvasive positive-pressure ventilation for this indication, five separate systematic reviews ${ }^{162-166}$ had consistently demonstrated a significant reduction in endotracheal intubation with both types of noninvasive ventilation. When this large trial was included in the metaanalysis, there was a trend toward reduction in endotracheal intubation with noninvasive positive-pressure ventilation (RR $0.55,95 \% \mathrm{CI}$ 0.29-1.03) and a significant reduction in endotracheal intubation with continuous positive airway pressure by mask (RR $0.42,95 \%$ CI 0.28 $0.63)$ relative to oxygen alone.

Notably, this recent large trial ${ }^{65}$ differed from most others, in that patients who met the criteria for treatment failure were allowed to cross over to one of the two forms of noninvasive ventilation rather than undergoing insertion of an endotracheal tube. Although the rate of endotracheal intubation did not differ between arms, a much higher proportion of patients in the oxygen arm crossed over to noninvasive ventilation (56/367 patients v. 5/346 from continuous positive airway pressure to noninvasive positive-pressure ventilation and 12/356 from noninvasive positive-pressure ventilation to continuous positive airway pressure). In addition, the proportion of patients who did not remain in their assigned treatment arm because of respiratory distress was significantly higher in the oxygen-only arm (8.4\% v. $3.4 \%$ for noninvasive positive-pressure ventilation and $1.4 \%$ for continuous positive airway pressure; $p<$ $0.001)$. Because of the potential for crossover in this trial to confound the outcomes of endotracheal intubation and hospital mortality, we considered the outcome of "treatment failure" in developing our final guideline statement. Pooled treatment failure for all trials was significantly lower for both noninvasive positivepressure ventilation (RR 0.36 , 95\% CI $0.25-$ 0.51 ) and continuous positive airway pressure (RR 0.23 , 95\% CI $0.17-0.32$ ). Including all trials, there was a trend toward lower hospital mortality (for noninvasive positive-pressure ventilation, RR 0.84 , 95\% CI 0.63-1.13; for continuous positive airway pressure, RR 0.73 , 95\% CI 0.51-1.05).

The literature on continuous positive airway pressure by mask has evolved over the past two decades, during which time co-interventions for cardiogenic pulmonary edema that may affect mortality, including use of acute revascularization techniques, has changed. Inclusion and exclusion criteria varied among the trials. All 15 trials from 2000 to 2009 excluded patients with cardiogenic shock. In addition, 9 of these 15 trials, and 8 of the 10 trials in the period 2005 through 2009, also excluded patients who required acute coronary revascularization ${ }^{48,53,56,61,62,64,65}$ or who had acute coronary syndrome. ${ }^{54,59}$ Hence, it is difficult to extend recommendations to these specific populations. An early RCT suggested that noninvasive positive-pressure ventilation was associated with a greater risk of myocardial infarction than was continuous positive airway pressure, ${ }^{45}$ but many subsequent RCTs have not confirmed this finding. $50,54,56,57,59,61,62,64,65$

\section{Statement}

- We recommend the use of either noninvasive positive-pressure ventilation or continuous positive airway pressure by mask in 
patients who have cardiogenic pulmonary edema and respiratory failure in the absence of shock or acute coronary syndrome requiring urgent coronary revascularization (grade 1 A recommendation).

\section{Acute lung injury}

Three RCTs have assessed noninvasive ventilation in patients with acute lung injury, including acute respiratory distress syndrome. Two trials on noninvasive positive-pressure ventilation included subgroups of patients with acute lung injury, but the numbers of events and patients were too small to allow interpretation (total of 30 patients in the two trials ${ }^{39,40}$ ). One RCT was published on the use of continuous positive airway pressure plus usual therapy versus usual therapy alone in patients with acute hypoxemic respiratory failure. ${ }^{37}$ One-third of these patients had associated acute or chronic cardiac disease, although the relative proportion of each and the precise definition of cardiac disease were not reported. In the subgroup of patients who did not have acute or chronic cardiac disease, the addition of continuous positive airway pressure did not affect endotracheal intubation (RR 0.86, 95\% CI $0.54-1.37$ ) or hospital mortality (RR 1.04, 95\% CI 0.6-1.7) but was associated with more adverse events (including four cardiac arrests), which suggested a potential for harm.

\section{Statements}

- We make no recommendation about the use of noninvasive positive-pressure ventilation in patients who have acute lung injury, because of a lack of RCTs.

- We recommend that continuous positive airway pressure not be used in patients who have acute lung injury (grade $1 \mathrm{C}$ recommendation).

\section{Severe community-acquired pneumonia in patients without COPD}

Two RCTs studied noninvasive positivepressure ventilation in patients with communityacquired pneumonia and acute hypoxemic respiratory failure but no prior history of COPD. In one trial, patients with COPD were included, and results for patients who did and did not have this condition were reported separately. ${ }^{38}$ In the subgroup of patients who did not have COPD $(n$ $=33$ ), the addition of noninvasive positivepressure ventilation did not reduce endotracheal intubation (6/16 v. 8/17 in control group) or hospital mortality (6/16 v. 4/17). In the other trial, which involved patients with acute hypoxemic respiratory failure but no underlying COPD, there was benefit (reduced endotracheal intubation and ICU mortality) for the subgroup of patients $(n=34)$ with severe communityacquired pneumonia. ${ }^{39}$ For these two small subgroups (67 patients in total) from two RCTs, the results were conflicting regarding the addition of noninvasive positive-pressure ventilation to usual therapy for patients with severe community-acquired pneumonia but no prior history of COPD (pooled results: RR $0.54,95 \% \mathrm{CI}$ 0.24-1.17 for endotracheal intubation and RR 0.70, 95\% CI 0.13-3.63 for hospital mortality). We did not identify any RCTs on the use of continuous positive airway pressure for patients with severe community-acquired pneumonia and without COPD.

\section{Statements}

- We make no recommendation about the use of noninvasive positive-pressure ventilation in patients who have severe communityacquired pneumonia and no prior history of COPD, because of insufficient evidence.

- We make no recommendation about the use of continuous positive airway pressure by mask in patients who have severe community-acquired pneumonia and no prior history of COPD, because of a lack of RCTs.

\section{Chest trauma}

There were two RCTs on the use of continuous positive airway pressure in patients with severe chest trauma: one for prevention and one for treatment of respiratory failure in patients without an endotracheal tube at the time of presentation. ${ }^{137,138}$ No RCTs have evaluated noninvasive positive-pressure ventilation for these indications. In the prevention trial, which included all patients with severe chest trauma regardless of whether they had respiratory distress ${ }^{137}$ co-interventions differed between treatment groups, the noninvasive ventilation group receiving epidural analgesia and the control group receiving systemic analgesia. In addition, the comparator to continuous positive airway pressure in this trial was intubation and mechanical ventilation. Hence, although the group receiving noninvasive ventilation had a shorter length of stay in the ICU and in hospital, the design of the study did not reflect current clinical practice, as endotracheal tubes are not usually inserted prophylactically for patients similar to those in the control group. The RCT involving patients with respiratory failure reported a lower mortality rate $(2 / 22 \mathrm{v}$. $7 / 21 ; p<0.01)$ for the group receiving continuous positive airway pressure by mask, ${ }^{138}$ but the small total number of patients $(n=43)$ and the single-centre design raise concerns regarding generalizability. 


\section{Statements}

- We make no recommendation about the use of noninvasive positive-pressure ventilation or continuous positive airway pressure in patients who have chest trauma without respiratory distress, because of a lack of RCTs.

- We make no recommendation about the use of noninvasive positive-pressure ventilation in patients who have chest trauma and respiratory distress, because of a lack of RCTs.

- We make no recommendation about the use of continuous positive airway pressure by mask in patients who have chest trauma and respiratory distress, because of insufficient evidence.

\section{Immunosuppression}

We identified two RCTs that evaluated the effect of noninvasive positive-pressure ventilation added to usual therapy in patients with immunosuppression (defined as receiving immunosuppressive therapy for solid organ or bone marrow transplant or immunosuppressive chemotherapy) who also had acute respiratory distress or failure. ${ }^{40,41}$ Both studies (total 92 patients) showed a reduction in endotracheal intubation (RR 0.46, 95\% CI 0.22-0.95) and a reduction in hospital mortality (RR 0.62 , 95\% CI $0.43-0.90$ ). However, members of the panel questioned the generalizability of the results from centres with highly experienced staff to other centres. No RCTs were found on the use of continuous positive airway pressure in this population.

\section{Statements}

- We suggest that noninvasive positivepressure ventilation be used for immunosuppressed patients who have acute respiratory failure (grade 2B recommendation).

- We make no recommendation about the use of continuous positive airway pressure by mask in immunosuppressed patients who have acute respiratory failure, because of a lack of RCTs.

\section{Bronchoscopy in patients with hypoxemia}

Patients with hypoxemia who undergo bronchoscopy are at risk of respiratory deterioration and need for endotracheal intubation. One RCT using noninvasive positive-pressure ventilation $^{118}$ and a second using continuous positive airway pressure by mask ${ }^{119}$ suggested benefit in_terms of oxygenation when these interventions were used during bronchoscopy. However, few patients were included (total of 56 for the two RCTs), and the impact on endotracheal intubation $(0.28,95 \%$ CI $0.05-1.64)$ was inconsistent.

\section{Statement}

- We make no recommendation about the use of either noninvasive positive-pressure ventilation or continuous positive airway pressure in patients who have hypoxemia and who undergo bronchoscopy, because of insufficient evidence.

\section{After intubation}

\section{Adjunct to early liberation}

Nine RCTs found that noninvasive positivepressure ventilation can be used as an alternative to continued invasive ventilation in patients who become clinically stable but still require ongoing ventilation (e.g., failure of spontaneous breathing trials but meeting criteria for control of pulmonary infection $^{72,73,75,76,78-82}$ ) (RR 0.49, 95\% CI $0.29-0.83$ for hospital mortality). However, six of the nine trials included only patients who had exacerbations of COPD. ${ }^{72,75,78-81}$ Two of the remaining three RCTs included both patients without COPD and a large proportion of patients with COPD (58\% ${ }^{76}$ and $\left.76 \%{ }^{73}\right)$. The pooled effect on hospital mortality for these three studies was not significant (RR 0.52, 95\% CI 0.15-1.85). The wide confidence intervals arose because of benefit in the two studies that had larger proportions of patients with COPD and no benefit in the single study that had fewer patients with COPD.

At this time, the literature supports use of noninvasive positive-pressure ventilation only in patients who have COPD because the minimal data on patients without this condition suggest no benefit. Because of methodologic limitations in these studies, as well as important safety, feasibility and cost limitations, the use of noninvasive positive-pressure ventilation for this indication requires both considerable expertise and the ability to closely monitor the patients, because urgent reintubation may be required.

No RCTs have been published on the use of continuous positive airway pressure by mask in this population.

\section{Statements}

- We suggest that noninvasive positivepressure ventilation be used to facilitate early liberation from mechanical ventilation in patients who have COPD, but only in centres that have expertise in this type of therapy (grade 2B recommendation).

- We make no recommendation about the use of noninvasive positive-pressure ventilation to facilitate early liberation from mechanical ventilation in patients who do not have COPD, because of insufficient evidence. 
- We make no recommendation about the use of continuous positive airway pressure by mask to facilitate early liberation from mechanical ventilation, because of a lack of RCTs.

\section{After planned extubation}

Noninvasive ventilation may prevent the need for reintubation if applied immediately after planned extubation. One small, low-quality trial assessed noninvasive positive-pressure ventilation after extubation and found no benefit. ${ }^{83}$ The study had limited generalizability because it included a high proportion of patients who had performed the extubation themselves. Members of the panel expressed concern regarding the feasibility and cost of noninvasive positive-pressure ventilation in this setting.

Four recent RCTs suggested benefit from noninvasive positive-pressure ventilation after extubation in patients who were at high risk of deterioration. ${ }^{84-87}$ High-risk patients were defined differently among the RCTs: 1) age greater than 65 years, cardiac failure as the cause of intubation or Acute Physiology and Chronic Health Evaluation (APACHE) II score greater than 12 at the time of extubation; $;{ }^{84}$ ) more than one of the following: failure of consecutive weaning trials, chronic cardiac failure, arterial pressure of carbon dioxide greater than $45 \mathrm{~mm} \mathrm{Hg}$ after extubation, more than one noncardiac comorbidity, weak cough or stridor after extubation not requiring immediate intubation; ${ }^{85} 3$ ) acute exacerbation of $\mathrm{COPD}^{86}$ or 4 ) history of chronic respiratory disease with ventilation for more than 48 hours and hypercapnia during the spontaneous breathing trial. ${ }^{87}$ Although the four trials defined higher risk differently, they reported consistent decreases in rates of reintubation (RR $0.42,95 \%$ CI $0.25-$ 0.70 ) and ICU mortality (RR $0.35,95 \%$ CI $0.16-$ 0.78 ) but less benefit in terms of hospital mortality (RR 0.66, 95\% CI 0.42-1.04).

Although these results are promising, we suggest that noninvasive positive-pressure ventilation be used in this setting only where there is expertise in both this type of therapy and invasive airway management. We did not identify any RCTs investigating the role of continuous positive airway pressure by mask in this population.

\section{Statements}

- We suggest that noninvasive positivepressure ventilation be used after planned extubation in patients who are considered to be at high risk of recurrent respiratory failure, but only in centres that have expertise in this type of therapy (grade $2 \mathrm{~B}$ recommendation).

- We suggest that noninvasive positivepressure ventilation not be used after planned extubation in patients who are considered to be at low risk of respiratory failure (grade $2 \mathrm{C}$ recommendation).

- We make no recommendation about the use of continuous positive airway pressure by mask after planned extubation, because of a lack of RCTs.

\section{Respiratory failure after extubation}

Noninvasive ventilation has been used in patients who experience respiratory failure during the postextubation period (generally considered to be 48-72 hours after extubation). Two RCTs have evaluated the addition of noninvasive positivepressure ventilation to usual care compared with usual care alone for postextubation respiratory failure, and both found no reduction in rates of reintubation (RR 1.03, 95\% CI 0.84-1.25)..$^{70,71}$ The larger, multicentre trial suggested potential harm, finding a higher rate of ICU mortality among patients receiving noninvasive positivepressure ventilation $(28 / 114 \mathrm{v} .15 / 107, p=$ 0.048). ${ }^{71}$ Notably, the earlier study excluded patients with COPD after the first of 4 years of recruitment, ${ }^{70}$ and in the second study too few patients with COPD were available to be analyzed separately. ${ }^{71}$ Others have raised concerns that noninvasive positive-pressure ventilation was not optimally applied in either trial. ${ }^{167,168}$ At present, safety concerns (consequences of delayed reintubation and increased mortality) and issues of feasibility (centre expertise) preclude recommendation of routine use of noninvasive positivepressure ventilation in this patient population.

We did not identify any RCTs evaluating use of continuous positive airway pressure by mask in this population.

\section{Statements}

- We suggest that noninvasive positivepressure ventilation not be routinely used in patients who do not have COPD and who have postextubation respiratory failure (grade $2 \mathrm{C}$ recommendation).

- We make no recommendation about the use of noninvasive positive-pressure ventilation in patients who have COPD and postextubation respiratory failure, because of insufficient evidence.

- We make no recommendation about the use of continuous positive airway pressure by mask in patients who have postextubation respiratory failure, because of a lack of RCTs.

\section{Postoperative setting}

Noninvasive ventilation may be used in the postoperative setting to either prevent or treat res- 
piratory failure. For prevention, noninvasive ventilation is added to usual care for all patients who undergo specified surgeries. For treatment, noninvasive ventilation is used only in patients who experience postoperative hypoxemia or early signs of respiratory failure. The potential benefit of these interventions when applied as part of routine postoperative care (i.e., for prevention of respiratory failure) may depend on the baseline risk of respiratory failure. This risk can arise from variables related to either the patient or the surgical procedure itself. ${ }^{16,170}$ For example, one trial of patients undergoing abdominal surgery ${ }^{110}$ included only high-risk patients as defined by a previously validated risk-scoring system, which included body mass index, the presence of cardiac comorbidities, COPD and an oncologic diagnosis. ${ }^{170}$ Unfortunately, other than this trial ${ }^{110}$ the literature comprises only studies that do not specify the risk level of the included patients.

\section{Prevention of respiratory failure}

For the purposes of this guideline we considered high-risk surgical procedures to include major vascular procedures, such as elective abdominal vascular surgery ${ }^{92}$ and elective thoracoabdominal vascular surgery. ${ }^{94}$ The average age of patients enrolled in these trials was about 65 years, which represents an additional risk factor for postoperative respiratory failure, and the risk due to patients' comorbidities was not specifically defined. ${ }^{169}$ Although cardiac and thoracic surgery may be considered high-risk procedures, the actual incidence of respiratory failure with these types of surgery is relatively low. ${ }^{89,91,95,97-99}$

For the purposes of these guidelines, low risk was necessarily defined by the surgical procedure alone, as no trials specified that their respective patient populations were uniformly at low risk. As such, trials of low-risk surgical procedures might have included patients with comorbidities that would place them in either high- or low-risk categories. Trials of the use of noninvasive ventilation in patients who underwent lowrisk surgical procedures were generally small and reported only physiologic outcomes or found no difference in endotracheal intubation,

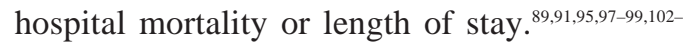
${ }_{107,109,111}$ The only exception was a recent large trial of continuous positive airway pressure by mask in 468 patients after cardiac surgery. ${ }^{101}$ There was a reduction in a composite end point of pulmonary complications (arterial pressure of oxygen/fraction of inspired oxygen $<100$, pneumonia or reintubation) and readmission to the ICU or an intermediate care unit. The authors found no differences in reintubation, mortality or length of stay. Although none of the trials involving patients who underwent low-risk surgery specified the patients' risk level in terms of associated comorbidities, the lack of evidence of effectiveness of either noninvasive positivepressure ventilation or continuous positive airway pressure in these heterogeneous populations implies a lack of evidence for low-risk patients.

One trial evaluated noninvasive positivepressure ventilation in patients considered at high risk of respiratory failure (because of associated comorbidities) who underwent abdominal surgery, considered a lower-risk procedure. ${ }^{110}$ The authors reported a nonsignficant reduction in reintubation during the postoperative period (0/21 v. $2 / 20)$. No trials evaluated continuous positive airway pressure for a specifically defined high-risk group of patients undergoing low-risk surgery.

Two RCTs evaluated continuous positive airway pressure by mask in addition to usual therapy or intermittent breathing exercises in patients who underwent high-risk surgical procedures, including elective open repair of abdominal aortic aneurysm or thoracoabdominal vascular surgery ${ }^{92,94}$ Neither trial specified the risk level of the patient population. Pooled results from these two trials showed a trend toward reduced rate of endotracheal intubation (RR 0.23, 95\% CI 0.05-1.03) but no difference in hospital mortality.

For prevention of respiratory failure after low-risk surgical procedures:

- We make no recommendation about the use of either noninvasive positive-pressure ventilation or continuous positive airway pressure by mask in low-risk patients after low-risk surgery, because of insufficient evidence.

- We make no recommendation about the use of noninvasive positive-pressure ventilation to prevent respiratory failure after cardiac surgery, because of a lack of RCTs, and no recommendation about the use of continuous positive airway pressure by mask in this setting, because of insufficient evidence.

- We make no recommendation about the use of either noninvasive positive-pressure ventilation or continuous positive airway pressure by mask in patients at high risk (because of associated comorbidity) to prevent respiratory failure after low-risk surgical procedures, because of insufficient evidence.

For prevention of respiratory failure after high-risk surgical procedures:

- We make no recommendation about the use of noninvasive positive-pressure ventilation to prevent respiratory failure after high-risk surgical procedures, because of a lack of RCTs. 
- We make no recommendation about the use of continuous positive airway pressure by mask to prevent respiratory failure after highrisk surgical procedures, because of insufficient evidence.

\section{Treatment of respiratory failure}

Two RCTs ${ }^{90,112}$ assessed the use of noninvasive ventilation to treat respiratory failure in the postoperative setting. One trial examined continuous positive airway pressure by mask in patients who experienced hypoxemia after abdominal surgery involving visceral exposure times exceeding 90 minutes, ${ }^{112}$ and the other evaluated noninvasive positive-pressure ventilation in patients who experienced hypoxemia and increased work of breathing after lung resection. ${ }^{90}$ Both RCTs found a reduction in rate of endotracheal intubation (RR $0.14,95 \%$ CI $0.03-0.62^{112}$ and RR $0.42,95 \%$ CI $0.17-1.00,{ }^{90}$ respectively). Patients who had underlying congestive heart failure and valvular heart disease were excluded from the abdominal surgery study. ${ }^{112}$ The current evidence is therefore limited, as few patients were enrolled in these studies and few experienced outcome events.

\section{Statements}

- We make no recommendation about the use of noninvasive positive-pressure ventilation in patients who have respiratory failure after abdominal surgery, because of a lack of RCTs.

- We suggest that continuous positive airway pressure be used in patients who have respiratory failure after abdominal surgery (grade $2 \mathrm{C}$ recommendation).

- We suggest that noninvasive positivepressure ventilation be used in patients who have respiratory failure after lung-resection surgery (grade $2 \mathrm{C}$ recommendation).

- We make no recommendation about the use of continuous positive airway pressure by mask in patients who have respiratory failure after lungresection surgery, because of a lack of RCTs.

\section{Optimal use of noninvasive ventilation}

All of the preceding statements have referred to the use of either noninvasive positive-pressure ventilation or continuous positive airway pressure by mask in specific populations. Several additional questions remain unanswered: Which interface is optimal: nasal, oronasal mask (mask covering nose and mouth), full face mask (mask covering entire face) or helmet? Which mode of noninvasive positive-pressure ventilation is optimal: pressure support ventilation, volume control ventilation or proportional assist ventilation? Is there a superior model of ventilator or optimal triggering? What is the role of humidification?

We searched the literature to address these questions and found that most studies were uncontrolled or used a randomized crossover rather than parallel design. We did not identify any trials on optimal triggering, ventilator type or use of humidification. Therefore, our statements in this area are limited.

\section{Choice of interface}

Two RCTs, with parallel design, compared use of an oronasal mask with use of a nasal mask in patients who had acute respiratory failure. ${ }^{125,126}$ Although there was no difference in endotracheal intubation or mortality, the oronasal mask was better tolerated. One small RCT (34 patients) compared the use of a full face mask with use of an oronasal mask. ${ }^{127}$ The study investigators reported better tolerance of the oronasal mask, but the small number of patients precludes any strong inferences.

\section{Statements}

- We suggest the use of an oronasal mask rather than a nasal mask in patients who have acute respiratory failure and who are receiving noninvasive positive-pressure ventilation (grade $2 \mathrm{C}$ recommendation).

- We make no recommendation about the use of an oronasal mask versus full face mask for noninvasive positive-pressure ventilation in patients who have acute respiratory failure, because of insufficient evidence.

- We make no recommendation about the use of an oronasal mask versus nasal or full face mask in patients who have acute respiratory failure and who are receiving continuous positive airway pressure by mask, because of a lack of RCTs.

\section{Preferred mode for noninvasive positive- pressure ventilation}

Two parallel-design RCTs compared the use of pressure support ventilation and proportional assist ventilation. ${ }^{148,149}$ Neither found differences in rates of intubation or mortality. In one RCT, different ventilator models were used in each of the two arms, ${ }^{149}$ a difference that may confound the better tolerance found in the group receiving proportional assist ventilation. The second RCT, which used the same model of ventilator to compare the two modes of ventilation, also reported better comfort and tolerance with proportional assist ventilation. ${ }^{148}$ Important methodologic issues limit inferences from these trials. Moreover, feasibility and cost considerations associ- 
ated with proportional assist ventilation preclude the widespread use of this mode of noninvasive positive-pressure ventilation.

\section{Statement}

- We make no recommendation about the use of proportional assist ventilation versus pressure support ventilation in patients who are receiving noninvasive positive-pressure ventilation for acute respiratory failure, because of insufficient evidence.

\section{Implementation}

Implementation of these guidelines may require clinician education, additional health care personnel, organizational change or additional resources (equipment or beds with cardiopulmonary monitoring) to ensure safe and appropriate application of noninvasive positive-pressure ventilation and continuous positive airway pressure. Timely endotracheal intubation may be required if noninvasive ventilation fails. Strategies for the implementation of these guidelines should be developed for each relevant clinician group (physicians in different clinical areas and with different levels of training and expertise, respiratory therapists and bedside nurses). ${ }^{171,172}$

\section{Updating}

We plan to update this guideline every four years (sooner if sufficient new data from RCTs become available).

\section{Discussion}

The guideline statements that we have developed for the use of noninvasive ventilation for patients in the acute care setting build on previous consensus conference statements ${ }^{152,153}$ and guidelines ${ }^{154,156,157}$ published by other societies. Our guideline is based on the most current, systematic and comprehensive review of RCTs in this area. We used GRADE methodology in our critical appraisal of the quality of the RCT evidence with respect to study validity. Moreover, we incorpor ated assessments of safety, feasibility and cost in developing our recommendations. Where there was insufficient RCT evidence to make a recommendation, we have indicated "no recommendation," which means that the evidence neither favours nor opposes the use of noninvasive ventilation in those clinical situations.

During the development of this guideline, we enlisted the help of a multidisciplinary panel of critical care physicians, pulmonary physicians and respiratory therapists, including methodolo- gists with expertise in evidence-based medicine and guideline development. To prepare for using the GRADE methodology, we educated the panel members in advance about use of this systematic and transparent method of grading the evidence and developing statements. After using a consensus process to develop our final statements, we obtained an anonymous agreement score for each statement from each panel member. In addition, this guideline was critiqued by external reviewers from two professional associations and by two international experts in noninvasive positivepressure ventilation research and application.

This guideline does not address the use of noninvasive ventilation in some clinical settings where it is currently used because of a lack of RCTs for either intervention. Some examples include use of noninvasive ventilation for acute respiratory failure in patients with cystic fibrosis or HIV/AIDS or in patients who have declined intubation and resuscitation. Although there is no RCT-level evidence to support effectiveness in these settings, the absence of such evidence does not preclude benefit. For these and other areas for which noninvasive ventilation is currently used, these technologies may be considered as possible treatment options. In some settings, experimental studies may be ethically challenging, and RCTs may never be conducted.

\section{Other guidelines}

The literature review and consensus processes used to arrive at the recommendations presented here are similar to those used for the British Thoracic Society guideline published in 2002,, ${ }^{154}$ and the scope and recommendations of our guidelines closely resemble those of the British guideline. However, for our guideline, we considered more recent literature (an additional 58 RCTs), used RCT evidence alone and used the GRADE methodology. The British Thoracic Society guideline includes recommendations for patients who have chest wall deformity or neuromuscular disease, decompensated obstructive sleep apnea, and cystic fibrosis or bronchiectasis, but recommendations for these patient groups were based on nonRCT evidence. Our guideline addresses several additional clinical settings: postoperative care, weaning from conventional mechanical ventilation, transition to spontaneous breathing and respiratory failure after extubation; it also includes more thorough review and discussion of the topic of immunocompromised patients. The British Thoracic Society guideline describes optimal application of and weaning from noninvasive positive-pressure ventilation, including monitoring requirements and guidance on setting up and running a noninvasive positive-pressure ventilation 
service. Our recommendations are limited to areas for which there is RCT evidence to make recommendations regarding the interface and modes of noninvasive positive-pressure ventilation.

The Indian Society of Critical Care Medicine published guidelines in 2006, ${ }^{156}$ using a more limited search strategy. In addition, individual panel members summarized each area of interest before meeting. The 10-member panel that prepared those guidelines used a consensus approach to reach their recommendations but did not use the GRADE methodology. They incorporated nonRCT evidence into weak recommendations for settings where we did not make any recommendation, such as severe community-acquired pneumonia. They also had a broader focus, including application of noninvasive positive-pressure ventilation, monitoring, location of use and initiating a service of this type. Although they made similarly strong recommendations for noninvasive positive-pressure ventilation in patients with cardiogenic pulmonary edema and exacerbation of COPD, their other recommendations tended to be stronger than those in our guideline. We also considered 24 new RCTs that were published since the release of these guidelines.

The most recent guidelines previous to ours were published in 2008 by a group of 28 experts from 12 German medical societies. ${ }^{157}$ Their recommendations are similar to ours for patients who have COPD or cardiogenic pulmonary edema. However, we differed from the German guidelines in our recommendations about use of noninvasive ventilation for immunocompromised patients, patients who are being weaned from mechanical ventilation and those who experience respiratory failure after extubation. The German guidelines made a strong grade A recommendation (where grade of recommendation was based on the study design) for use of noninvasive positive-pressure ventilation for these groups of patients, but we were more conservative in our level of recommendation because of lesser quantity and/or quality of evidence to support the use of this type of therapy in these settings. Importantly, because there were no RCTs, we did not include an assessment of noninvasive ventilation for patients who have declined invasive mechanical ventilation. In contrast, the German guidelines recommend (level B recommendation) that noninvasive positivepressure ventilation is an acceptable alternative. Furthermore, we limited our guidelines to adults, whereas the German guidelines included recommendations for children as well (level C).

\section{Limitations}

In critiquing this guideline using the AGREE Critical Appraisal Instrument, we found that it meets 20 of the 23 items (organized within 6 domains). ${ }^{161}$ Specifically, we fulfilled only one of the three criteria within the "stakeholder involvement domain" of the instrument, because we did not include emergency department physicians or nurses in the development process, nor did we take patients' perspectives into account. We did not conduct a formal economic evaluation or incorporate existing economic evaluations of noninvasive ventilation into the development of this guideline. We pretested the guidelines informally among the target users. However, the development of formal strategies for implementing the guidelines and the testing of those strategies in acute and critical care settings are the subject of ongoing research. The aim of this research is to identify the most effective and most cost-effective strategies adapted to the local level.

\section{Knowledge gaps}

There are several topics for which we could not make recommendations because of insufficient RCT evidence. Areas we suggest for future research include the use of noninvasive ventilation for severe community-acquired pneumonia, asthma, acute lung injury and chest trauma; for early liberation from mechanical ventilation; after planned extubation; and in the postoperative setting. Important unresolved technical issues that require further research include the optimal ventilator, mode of ventilation, trigger, interface and level of humidification.

\section{Conclusion}

Noninvasive ventilation is an important option in the management of patients who are at risk of or who have respiratory failure in the acute care setting. However, there is considerable variability in its use. ${ }^{173,174}$ These guidelines provide a means to reduce variations in practice while applying evidence-based recommendations for care of these acutely ill patients. The guidelines were developed within the context of the Canadian health care system, but they are founded on RCTs from around the world. On the basis of these characteristics, we believe that these recommendations are generalizable and potentially useful to all clinicians who care for patients who are at risk of or who have acute respiratory failure in the acute care setting.

\section{References}

1. Meduri GU, Conoscenti CC, Menashe P, et al. Noninvasive face mask ventilation in patients with acute respiratory ventilation. Chest 1989;95:865-70.

2. Meduri GU, Abou-Shala N, Fox RC, et al. Noninvasive face mask mechanical ventilation in patients with acute hypercapnic respiratory failure. Chest 1991;100:445-54.

3. Foglio C, Vitacca M, Quadri A, et al. Acute exacerbations in severe COLD patients: treatment with positive pressure ventilation by nasal mask. Chest 1992;101:1533-8. 
4. Marino W. Intermittent volume cycled mechanical ventilation via nasal mask in patients with respiratory failure due to COPD. Chest 1991;99:681-4.

5. Elliott MW, Steven MH, Phillips GD, et al. Non-invasive ventilation for acute respiratory failure. BMJ 1990;300:358-60.

6. Servera E, Perez M, Marin J, et al. Noninvasive nasal mask ventilation beyond the ICU for an exacerbation of chronic respiratory insufficiency. Chest 1995;108:1572-6.

7. Benhamou D, Girault C, Faure C, et al. Nasal mask ventilation in acute respiratory failure: experience in elderly patients. Chest 1992;102:912-7.

8. Brochard L, Isabey D, Piquet J, et al. Reversal of acute exacerbations of chronic obstructive lung disease by inspiratory assistance with a face mask. N Engl J Med 1990;323:1523-30.

9. Meduri GU, Turner RE, Abou-Shala N, et al. Noninvasive positive pressure ventilation via face mask. First line intervention in patients with acute hypercapnic and hypoxemic respiratory failure. Chest 1996;109:179-93.

10. Väisänen IT, Räsänen J. Continuous positive airway pressure and supplemental oxygen in the treatment of cardiogenic pulmonary edema. Chest 1987;92:481-5.

11. Hoffmann B, Welte T. The use of noninvasive pressure support ventilation for severe respiratory insufficiency due to pulmonary oedema. Intensive Care Med 1999;25:15-20.

12. Kelly AM, Georgakas C, Bau S, et al. Experience with the use of continuous positive airway pressure (CPAP) therapy in the emergency management of acute severe cardiogenic pulmonary oedema. Aust N Z J Med 1997;27:319-22.

13. Sacchetti AD, Harris RH, Paston $\mathrm{C}$, et al. Bi-level positive airway pressure support system use in acute congestive heart failure: preliminary case series. Acad Emerg Med 1995;2:714-8.

14. Bott J, Carroll MP, Conway JH, et al. Randomised controlled trial of nasal ventilation in acute ventilatory failure due to chronic obstructive airways disease. Lancet 1993;341:1555-7.

15. Brochard L, Mancebo J, Wysocki M, et al. Noninvasive ventilation for acute exacerbations of chronic obstructive pulmonary disease. N Engl J Med 1995;333:817-22.

16. Kramer N, Meyer TJ, Meharg J, et al. Randomized, prospective trial of noninvasive positive pressure ventilation in acute respiratory failure. Am J Respir Crit Care Med 1995;151:1799-806.

17. Angus RM, Ahmed MM, Fenwick LJ, et al. Comparison of the acute effects on gas exchange of nasal ventilation and doxapram in exacerbations of chronic obstructive pulmonary disease. Tho$\operatorname{rax} 1996 ; 51: 1048-50$.

18. Celikel T, Sungur M, Ceyhan B, et al. Comparison of noninvasive positive pressure ventilation with standard medical therapy in hypercapnic acute respiratory failure. Chest 1998;114:1636-42.

19. Avdeev SN, Tret'iakov AV, Grigor'iants RA, et al. [Study of the use of noninvasive ventilation of the lungs in acute respiratory insufficiency due to exacerbation of chronic obstructive pulmonary disease]. Anesteziol Reanimatol 1998;(3):45-51. Russian.

20. Plant PK, Owen JL, Elliott MW. Early use of non-invasive ventilation for acute exacerbations of chronic obstructive pulmonary disease on general respiratory wards: a multicentre randomized controlled trial. Lancet 2000;355:1931-5.

21. Barbé F, Togores B, Rubi M, et al. Noninvasive ventilatory support does not facilitate recovery from acute respiratory failure in chronic obstructive pulmonary disease. Eur Respir J 1996;9:1240-5

22. del Castillo D, Barrot E, Laserna E, et al. Ventilación no invasiva por soporte de presion en pacientes con enfermedad pumonar obstructiva cronica en insuficiencia respiratoria aguda hipercapnica ingresados en una unidad de hospitalizacion convencional de neumologia. Med Clin (Barc) 2003;120:647-51.

23. Collaborative Research Group of Noninvasive Mechanical Ventilation for Chronic Obstructive Pulmonary Disease. Early use of non-invasive positive pressure ventilation for acute exacerbations of chronic obstructive pulmonary disease: a multicentre randomized controlled trial. Chin Med J (Engl) 2005;118:2034-40.

24. Dhamija A, Tyagi $\mathrm{P}$, Caroli $\mathrm{R}$, et al. Noninvasive ventilation in mild to moderate cases of respiratory failure due to acute exacerbation of chronic obstructive pulmonary disease. Saudi Med J 2005;26:887-90.

25. Dikensoy O, Ikidag B, Filiz A, et al. Comparison of non-invasvie ventilation and standard medical therapy in acute hypercapnic respiratory failure: a randomised controlled study at a tertiary health centre in SE Turkey. Int J Clin Pract 2002;56:85-8.

26. Liao X, Li Q, Lin K, et al. Non-invasive positive pressure ventilation for early treatment of respiratory failure due to exacerbation of chronic obstructive pulmonary disease: a random controlled trial. Acta Acad Med Mil Tert 2004;26:739-41.

27. Marvisi M, Brianti M, Marani G, et al. Acute antiarrhythimic effects of bi-level positive pressure ventilation in patients with acute respiratory failure caused by chronic obstructive pulmonary disease: a randomized clinical trial. Respiration 2004;71:152-8.

28. Matuska P, Pilarova O, Merta Z, et al. [Non-invasive ventilation support in patients with acute exacerbation of chronic obstructive pulmonary disease (COPD)]. Vnitr Lek 2006;52:241-8. Czech.

29. Pastaka C, Kastikas K, Karetsi E, et al. Non-invasive ventilation in chronic hypercapnic COPD patients with exacerbation and a pH of 7.35 and higher. Eur J Intern Med 2007;18:524-30.

30. Zhou R, Chen $\mathrm{P}$, Luo $\mathrm{H}$, et al. [Effects of noninvasive positive pressure ventilation on gas exchange and patients' transformation in chronic obstructive pulmonary disease and respiratory failure]. Hunan Yi Ke Da Xue Xue Bao 2001;26:261-2. Chinese.

31. Keenan SP, Powers CE, McCormack DG. Noninvasive positivepressure ventilation in patients with milder chronic obstructive pulmonary disease exacerbations: a randomized controlled trial. Respir Care 2005;50:610-6.

32. Jolliet P, Tassaux D, Thouret JM, et al. Beneficial effects of helium:oxygen noninvasive pressure support in patients with decompensated chronic obstructive pulmonary disease. Crit Care Med 1999;27:2422-9.

33. Jolliet P, Tassaux D, Roeseler J, et al. Helium-oxygen versus air-oxygen noninvasive pressure support in decompensated chronic obstructive disease: a prospective multicenter study. Crit Care Med 2003;31:878-84

34. Holley MT, Morrissey TK, Seaberg DC, et al. Ethical dilemmas in a randomized trial of asthma treatment: Can Bayesian statistical analysis explain the results? Acad Emerg Med 2001;8:1128-35.

35. Soroksky A, Stav D, Shpirer I. A pilot prospective, randomized, placebo-controlled trial of bilevel positive airway pressure in acute asthmatic attack. Chest 2003;123:1018-25.

36. Soma T, Hino M, Kida K, et al. A prospective and randomized study for improvement of acute asthma by non-invasive positive pressure ventilation (NPPV). Intern Med 2008;47:493-501

37. Delclaux C, L'Her E, Alberti C, et al. Treatment of acute hypoxemic nonhypercapnic respiratory insufficiency with continuous positive airway pressure delivered by a face mask: a randomized controlled trial. JAMA 2000;284:2352-60.

38. Confalonieri M, Potena A, Carbone G, et al. Acute respiratory failure in patients with severe community-acquired pneumonia: a prospective randomized evaluation of noninvasive ventilation. Am J Respir Crit Care Med 1999;160:1585-91.

39. Ferrer M, Esquinas A, Leon M, et al. Noninvasive ventilation in severe acute hypoxemic respiratory failure: a randomized clinical trial. Am J Respir Crit Care Med 2003;168:1438-44.

40. Antonelli M, Conti G, Bufi M, et al. Noninvasive ventilation for treatment of acute respiratory failure in patients undergoing solid organ transplantation: a randomized trial. JAMA 2000;283:235-41.

41. Hilbert G, Gruson D, Vargas F, et al. Noninvasive ventilation in immunosuppressed patients with pulmonary infiltrates, fever, and acute respiratory failure. $N$ Engl J Med 2001;344:481-7.

42. Räsänen J, Heikkila J, Downs J, et al. Continuous positive airway pressure by face mask in acute cardiogenic pulmonary edema. Am J Cardiol 1985;55:296-300.

43. Bersten AD, Holt AW, Vedig AE, et al. Treatment of severe cardiogenic pulmonary edema with continuous positive airway pressure delivered by face mask. N Engl J Med 1991;325:1825-30.

44. Lin M, Yang YF, Chiang HT, et al. Reappraisal of continuous positive airway pressure therapy in acute cardiogenic pulmonary edema: short-term results and long-term follow-up. Chest 1995; 107:1379-86.

45. Mehta S, Jay GD, Woolard RH, et al. Randomized, prospective trial of bilevel versus continuous positive pressure in acute pulmonary edema. Crit Care Med 1997;25:620-8.

46. Takeda S, Takano T, Ogawa R. The effect of nasal continuous positive airway pressure on plasma endothelin- 1 concentrations in patients with severe cardiogenic pulmonary edema. Anesth Analg 1997;84:1091-6.

47. Takeda S, Nejima J, Takano T, et al. Effect of nasal continuous positive airway pressure on pulmonary edema complicating acute myocardial infarction. Jpn Circ J 1998;62:553-8.

48. Masip J, Betbese AJ, Paez J, et al. Non-invasive pressure support ventilation versus conventional oxygen therapy in acute cardiogenic pulmonary oedema: a randomized trial. Lancet 2000;356:2126-32.

49. Levitt MA. A prospective, randomized trial of BiPAP in severe acute congestive heart failure. J Emerg Med 2001;21:363-9.

50. Park M, Lorenzi-Filho G, Fetrim MI, et al. Oxygen therapy, continuous positive airway pressure, or noninvasive bilevel positive pressure ventilation in the treatment of acute cardiogenic pulmonary edema. Arq Bras Cardiol 2001;76:221-30.

51. Kelly CA, Newby DE, McDonagh TA, et al. Randomised controlled trial of continous positive airway pressure and standard oxygen therapy in acute pulmonary oedema. Eur Heart J 2002; 23:1379-86

52. Cross AM, Cameron P, Kierce M, et al. Non-invasive ventilation in acute respiratory failure: a randomized comparison of 
continuous positive airway pressure and bi-level positive airway pressure. Emerg Med J 2003;20:531-4.

53. Nava S, Carbone G, DiBattista N, et al. Noninvasive ventilation in cardiogenic pulmonary edema: a multicenter, randomized trial. Am J Respir Crit Care Med 2003;168:1432-7.

54. Bellone A, Monari A, Cortellaro F, et al. Myocardial infarction rate in acute pulmonary edema: noninvasive pressure support ventilation versus continuous positive airway pressure. Crit Care Med 2004;32:1860-5.

55. L'Her E, Duquesne F, Girou E, et al. Noninvasive continuous positive airway pressure in elderly cardiogenic pulmonary edema patients. Intensive Care Med 2004;30:882-8

56. Park M, Sangean MC, Volpe M, et al. Randomized, prospective trial of oxygen, continuous positive airway pressure, and bileve positive airway pressure by face mask in acute cardiogenic pulmonary edema. Crit Care Med 2004;32:2407-15.

57. Bellone A, Vettorello M, Monari A, et al. Noninvasive pressure support ventilation vs. continuous positive airway pressure in acute hypercapnic pulmonary edema. Intensive Care Med 2005; 31:807-11

58. Lin M, Chiang HT. The efficacy of early continuous positive airway pressure therapy in patients with acute cardiogenic pulmonary edema. J Formos Med Assoc 1991;90:736-43.

59. Ferrari G, Olliveri F, De Filippi G, et al. Noninvasive positive airway pressure and risk of myocardial infarction in acute cardiogenic pulmonary edema: continuous positive airway pressure vs noninvasive positive pressure ventilation. Chest 2007;132:1804-9.

60. Bellone A, Barbieri A, Ricci C, et al. Acute effects of non-invasive ventilatory support on functional mitral regurgitation in patients with exacerbation of congestive heart failure. Intensive Care Med 2002;28:1348-50.

61. Moritz F, Brousse B, Gellee B, et al. Continuous positive airway pressure versus bilevel noninvasive ventilation in acute cardiogenic pulmonary edema: a randomized multicenter trial. Ann Emerg Med 2007;50:666-75.

62. Rusterholtz T, Bollaert P, Feisssel M, et al. Continuous positive airway pressure vs. proportional assist ventilation for noninvasive ventilation in acute cardiogenic pulmonary edema. Intensive Care Med 2008;35:840-6.

63. Chadda K, Annane D, Hart N, et al. Cardiac and respiratory effects of continuous positive airway pressure and noninvasive ventilation in acute cardiac pulmonary edema. Crit Care Med 2002;30:2457-61.

64. Crane SD, Elliott MW, Gilligan P, et al. Randomised controlled comparison of continuous positive airways pressure, bilevel non-invasive ventilation, and standard treatment in emergency department patients with acute cardiogenic pulmonary oedema. Emerg Med J 2004;21:155-61.

65. Gray A, Goodacre S, Newby DE, et al. for the 3CPO Trialists. Noninvasive ventilation in acute cardiogenic pulmonary edema N Engl J Med 2008;359:142-51.

66. Hao C, Luo X, Liu Y. Treatment of severe cardiogenic pulmonary edema with continuous positive airway pressure by nasal mask. Acta Acad Med Jiangxi 2002;42:48-50.

67. Li X, Zhao W. The treatment of acute cardiogenic pulmonary edema with noninvasive ventilation. Chongqing Med J 2004;34:575-6.

68. Väisänen IT, Räsänen J. Continuous positive airway pressure and supplemental oxygen in the treatment of cardiogenic pulmonary edema. Chest 1997;92:481-5.

69. Moritz F, Benichou J, Vanheste M, et al. Boussignac continuous positive airway pressure device in the emergency care of acute cardiogenic pulmonary oedema: a randomized pilot study. Eur J Emerg Med 2003;10:204-8.

70. Keenan SP, Powers C, McCormack DG, et al. Noninvasive positive-pressure ventilation for post-extubation respiratory distress: a randomized controlled trial. JAMA 2002;287:3238-44.

71. Esteban A, Ferguson ND, Frutos-Vivar F, et al. Non-invasive positive pressure ventilation does not prevent reintubation and may be harmful in patients with postextubation respiratory distress: results of a randomized controlled trial. N Engl J Med 2004;350:2452-60.

72. Nava S, Ambrosino N, Clini E, et al. Noninvasive mechanical ventilation in the weaning of patients with respiratory failure due to chronic obstructive pulmonary disease: a randomized controlled trial. Ann Intern Med 1998;128:721-8.

73. Girault C, Daudenthun I, Chevron V, et al. Noninvasive ventilation as a systematic extubation and weaning technique in acuteon-chronic respiratory failure: a prospective, randomized controlled study. Am J Respir Crit Care Med 1999;160:86-92.

74. Hill NS, Lin D, Levy M, et al. Noninvasive positive pressure ventilation (NPPV) to facilitate extubation after acute respiratory failure: a feasibility study. Am J Respir Crit Care Med 2000; 161:B18.

75. Chen J, Qiu D, Tao D. [Time for extubation and sequential noninvasive mechanical ventilation in COPD patients with exacer- bated respiratory failure who received invasive ventilation] Zhongua Jie He He Hu Xi Za Ahi 2001;24:99-100. Chinese.

76. Ferrer M, Esquinas A, Arancibia F, et al. Noninvasive ventilation during persistent weaning failure. Am J Respir Crit Care Med 2003;168:70-6.

77. Rabie GM, Mohamed AZ, Mohamed R. Noninvasive ventilation in the weaning of patients with acute-on-chronic respiratory failure due to COPD. Chest 2004;126(Suppl):755S.

78. Wang X, Due X, Zhang W. Observation of the effect and the time for extubation and sequential noninvasive mechanical ventilation in COPD patients with exacerbated respiratory failure who received invasive ventilation. Shandong Med J 2004;44:4-6.

79. Zheng R, Liu L, Yang Yi, et al. Prospective randomized controlled clinical study of sequential non-invasive following invasive mechanical ventilation in patients with acute respiratory failure induced by COPD. Chin J Emerg Med 2005;14:21-5.

80. Zou SH, Zou R, Chen P, et al. [Application of sequential noninvasive following invasive mechanical ventilation in COPD patients with severe respiratory failure by investigating the appearance of the pulmonary-infection-control-window]. Zhong Nan Da Xue Xue Bao Yi Xue Ban 2006;31:120-4. Chinese.

81. Pulmonary infection control window in treatment of severe respiratory failure of chronic obstructive pulmonary diseases: a prospective, randomized controlled, multi-centre study. Collaborating Research Group for Noninvasive Mechanical Ventilation of Chinese Respiratory Society. Chin Med J (Engl) 2005;118:1589-94

82. Trevisan CE, Vieira SR. Research group in mechanical ventilation weaning. Crit Care 2008;12:R51.

83. Jiang JS, Kao SJ, Wang SN. Effect of early application of biphasic positive airway pressure on the outcome of extubation in ventilator weaning. Respirology 1999;4:161-5.

84. Ferrer M, Valencia M, Nicola JM, et al. Early noninvasive ventilation averts extubation failure in patients at risk: a randomized trial. Am J Respir Crit Care Med 2006;173:164-70.

85. Nava S, Gregoretti C, Fanfulla F, et al. Noninvasive ventilation to prevent respiratory failure after extubation in high-risk patients. Crit Care Med 2005;33:2465-70.

86. Luo H, Cheng P, Zhou R. [Sequential BiPAP following invasive mechanical ventilation in COPD patients with hypercapnic respiratory failure]. Hunan Yi Ke Da Xue Xue Bao 2001;26:563-5. Chinese.

87. Ferrer M, Sellares J, Valencia M, et al. Non-invasive ventilation after extubation in hypercapnic patients with chronic respiratory disorder: randomized controlled trial. Lancet 2009;374:1082-8.

88. Putensen C, Hormann C, Baum M, et al. Comparison of mask and nasal continuous positive airway pressure after extubation and mechanical ventilation. Crit Care Med 1993;21:357-62.

89. Aguiló R, Togores B, Pons S, et al. Noninvasive ventilatory support after lung resectional surgery. Chest 1997;112:117-21.

90. Auriant I, Jallot A, Herve P, et al. Noninvasive ventilation reduces mortality in acute respiratory failure following lung resection. Am J Respir Crit Care Med 2001;164:1231-5.

91. Perrin C, Jullien V, Venissa N, et al. Prophylactic use of noninvasive ventilation in patients undergoing lung resectional surgery. Respir Med 2007;101:1572-8.

92. Böhner H, Kindgen-Milles D, Grust A, et al. Prophylactic nasal continous positive airway pressure after major vascular surgery: results of a prospective randomized trial. Langenbecks Arch Surg 2002;387:21-6.

93. Fagevik Olsén M, Wennberg E, Johnsson E, et al. Randomized clinical study of the prevention of pulmonary complications after thoracoabdominal resection by two different breathing techniques. Br J Surg 2002;89:1228-34.

94. Kindgen-Milles D, Muller E, Buhl R, et al. Nasal-continuous positive airway pressure reduces pulmonary morbidity and length of hospital stay following thoracoabdominal aortic surgery. Chest 2005;128:821-8.

95. Larsen KR, Ingwersen U, Bertelsen MT, et al. [Prevention of postoperative pulmonary complications after cardiac and pulmonary surgery]. Ugeskr Lager 1994;156:5689-92. Danish.

96. Andersen JM, Olesen KP, Eikard B, et al. Periodic continuous positive airway pressure, CPAP, by mask in the treatment of atelectasis. Eur J Respir Dis 1980;61:20-5.

97. Gust R, Gottschalk A, Schmidt H, et al. Effects of continuous (CPAP) and bi-level positive airway pressure (BiPAP) on extravascular lung water after extubation of the trachea in patients following coronary artery bypass grafting. Intensive Care Med 1996;22:1345-50.

98. Pasquina P, Merlani P, Granier JM, et al. Continuous positive airway pressure versus noninvasive pressure support ventilation to treat atelectasis alter cardiac surgery. Anesth Analg 2004;99:1001-8.

99. Jousela I, Räsänen J, Verkkala K, et al. Continuous positive airway pressure by mask in patients after coronary surgery. Acta Anaesthesiol Scand 1994;38:311-6.

100. Coimbra VR, Lara Rde A, Flores EG, et al. Application of non- 
invasive ventilation in acute respiratory failure after cardiovascular surgery. Arq Bras Cardiol 2007;89:270-6.

101. Zarbock A, Mueller E, Netzer S, et al. Prophylactic nasal continuous positive airway pressure following cardiac surgery protects from postoperative pulmonary complications. Ches 2009;135:1252-9.

102. Ebeo CT, Benotti PN, Byrd RP, et al. The effect of bi-level positive airway pressure on postoperative pulmonary function following gastric surgery for obesity. Respir Med 2002;96:672-6.

103. Gaszynski T, Tokarz A, Piotrowski D, et al. Boussignac CPAP in the postoperative period in morbidly obest patients. Obes Surg 2007; 17:452-6.

104. Joris JL, Sottiaux TM, Chiche JD, et al. Effect of bi-level positive airway pressure (BiPAP) nasal ventilation on the postoperative pulmonary restrictive syndrome in obese patients undergoing gastroplasty. Chest 1997;111:665-70.

105. Carlsson C, Sonden B, Thylen U. Can postoperative continuous positive airway pressure (CPAP) prevent pulmonary complications after abdominal surgery? Intensive Care Med 1981;7:225-9.

106. Denehy L, Carroll S. A randomized controlled trial comparing periodic mask CPAP with physiotherapy after abdominal surgery. Physiother Res Int 2001;6:236-50.

107. Lindner KH, Lotz P, Ahnefeld FW. Continuous positive airway pressure effect on functional residual capacity, vital capacity and its subdivisions. Chest 1987;92:66-70.

108. Lotz P, Hiese U, Schaffer J, et al. The effect of intraoperative PEEP-ventilation and postoperative CPAP breathing on the postoperative pulmonary function following upper abdominal surgery. Anaesthesist 1984;33:177-88.

109. Ricksten SE, Bengtsson A, Scoderberg C, et al. Effects of periodic positive airway pressure by mask on postoperative pulmonary function. Chest 1986;89:774-81.

110. Vartanova IV, Khrapov KN, Polushin YS. Use of noninvasive ventilation in patients at high postoperative risk for cardiopulmonary complications. Anesteziol Reanimatol 2007;:17-19.

111. Stock MC, Downs JB, Gauer PK, et al. Prevention of postoperative pulmonary complications with CPAP, incentive spirometry and conservative therapy. Chest 1985;87:151-7.

112. Squadrone V, Coha M, Cerutti E, et al. Continuous positive airway pressure for treatment of postoperative hypoxemia: a randomized controlled trial. JAMA 2005;293:589-95.

113. Nørregaard O, Jensen TM, Vindelev P. Effects of inspiratory pressure support on oxygenation and central haemodynamics in the normal heart during the postoperative period. Respir Med 1996;90:415-7.

114. Baillard C, Fosse JP, Sebbane M, et al. Noninvasive ventilation improves preoxygenation before intubation of hypoxic patients. Am J Respir Crit Care Med 2006;174:171-7.

115. Cressey DM, Berthoud MC, Reilly CS. Effectiveness of continuous positive airway pressure to enhance pre-oxygenation in morbidly obese women. Anaesthesia 2001;56:670-75.

116. Patel RG, Petrini MF. Respiratory muscle performance, pulmonary mechanics, and gas exchange between the BiPAP S/T-D system and the servo ventilator $900 \mathrm{C}$ with bilevel positive airway pressure ventilation following gradual pressure support weaning. Chest 1998;114:1390-6.

117. Leman P, Greene S, Whelan K, et al. Simple lightweight disposable continuous positive airways pressure mask to effectively treat acute pulmonary oedema: randomized controlled trial. Emerg Med Australas 2005;17:224-30.

118. Antonelli M, Conti G, Rocco M, et al. Noninvasive positivepressure ventilation vs. conventional oxygen supplementation in hypoxemic patients undergoing diagnostic bronchoscopy. Chest 2002; 121:1149-54.

119. Maitre B, Jaber S, Maggiore SM, et al. Continuous positive airway pressure during fiberoptic bronchoscopy in hypoxemic patients: a randomized double-blind study using a new device. Am J Respir Crit Care Med 2000;162:1063-7.

120. Antonelli M, Conti G, Rocco M, et al. A comparison of noninvasive positive-pressure ventilation and conventional mechanical ventilation in patients with acute respiratory failure. $N$ Engl J Med 1998;339:429-35.

121. Conti G, Antonelli M, Navalesi P, et al. Noninvasive vs. conventional mechanical ventilation in patients with chronic obstructive pulmonary disease after failure of medical treatment in the ward: a randomized trial. Intensive Care Med 2002;28:1701-7.

122. Honrubia T, Garcia Lopez FJ, Franco N, et al. Noninvasive vs conventional mechanical ventilation in acute respiratory failure: a multicenter, randomized controlled trial. Chest 2005;128:3916-24.

123. Li J, Zhang D, Huang X, et al. Comparison of healing effect of noninvasive positive pressure ventilation and invasive positive pressure ventilation in patients in acute respiratory failure. Chin $J$ Crit Care 2003;23:528-30.

124. Matic I, Sakic-Zdravcevic K, Jurjevic M. Comparison of invasive and noninvasive mechanical ventilation for patients with chronic obstructive pulmonary disease: randomized prospective study. Period Biol 2007;109:137-45.

125. Kwok H, McComack J, Cece R, et al. Controlled trial of oronasal versus nasal mask ventilation in the treatment of acute respiratory failure. Crit Care Med 2003;31:468-73.

126. Girault C, Briel A, Benichou J, et al. Interface strategy during noninvasive positive pressure ventilation for hypercapnic acute respiratory failure. Crit Care Med 2009;37:124-31.

127. Cuvelier A, Pujol W, Pramil S, et al. Cephalic versus oronasa mask for noninvasive ventilation in acute hypercapnic respiratory failure. Intensive Care Med 2009;35:519-26.

128. Antón A, Tarrega J, Giner J, et al. Acute physiologic effects of nasal and full-face masks during noninvasive positive-pressure ventilation in patients with acute exacerbations of chronic obstructive pulmonary disease. Respir Care 2003;48:922-5.

129. Gregoretti C, Confalonieri M, Navalesi P, et al. Evaluation of patient skin breakdown and comfort with a new face mask for non-invasive ventilation: a multicenter study. Intensive Care Med 2002;28:278-84.

130. Patroniti N, Foti G, Maaflo A, et al. Head helmet versus face mask for non-invasive continuous positive airway pressure: a physiological study. Intensive Care Med 2003;29:1680-7.

131. Chen R, Zhang X, He G. [Modification of facial mask on the dead space effect in non-invasive mask ventilation]. Xhonghua Jie He He Hu Xi Za Zhi 2000;23:734-6. Chinese.

132. Schneider E, Duale C, Vaille JL, et al. Comparison of tolerance of facemask vs. mouthpiece for non-invasive ventilation. Anaesthesia 2006;61:20-3.

133. Vargas F, Thille A, Lyazidi A, et al. Helmet with specific settings versus facemask for noninvasive ventilation. Crit Care Med 2009;37:1921-8.

134. Fraticelli AT, Lellouch F, L'Her E, et al. Physiological effects of different interfaces during noninvasive ventilation for acute respiratory failure. Crit Care Med 2009;37:939-45.

135. Choo-kang YFJ, Grant IWB. Comparison of two methods of administering bronchodilator aerosols in asthmatic patients. BMJ 1975;2:119-20.

136. Nava S, Karakurt S, Rampulla C, et al. Salbutamol delivery during non-invasive mechanical ventilation in patients with chronic obstructive pulmonary disease: a randomized, controlled study. Intensive Care Med 2001;27:1627-35.

137. Bolliger CT, Van Eeden SF. Treatment of multiple rib fractures. Randomized controlled trial comparing ventilatory with nonventilatory management. Chest 1990;97:943-8.

138. Gunduz M, Unlugenc H, Ozalevli M, et al. A comparative study of continuous positive airway pressure (CPAP) and intermittent positive pressure ventilation (IPPV) in patients with flail chest. Emerg Med J 2005;22:325-9.

139. Martin TJ, Hovis JD, Costantino JP, et al. A randomized, prospective evaluation of noninvasive ventilation for acute respiratory failure. Am J Respir Crit Care Med 2000;161:807-13.

140. Thys F, Roeseler J, Reynaert M, et al. Noninvasive ventilation for acute respiratory failure: a prospective randomized placebocontrolled trial. Eur Respir J 2002;20:545-55.

141. Wood KA, Lewis L, Von Harz B, et al. The use of noninvasive positive pressure ventilation in the emergency department: results of a randomized clinical trial. Chest 1998;113:1339-46.

142. Wysocki M, Tric L, Wolff MA, et al. Noninvasive pressure support ventilation in patients with acute respiratory failure. A randomized comparison with conventional therapy. Chest 1995; 107:761-8.

143. Jaber S, Chanques G, Matecki S, et al. Comparison of the effects of heat and moisture exchangers and heated humidifiers on ventilation and gas exchange during non-invasive ventilation. Intensive Care Med 2002;28:1590-4.

144. Lellouche F, Maggiore SM, Deye N, et al. Effect of the humidification device on the work of breathing during noninvasive ventilation. Intensive Care Med 2002;28:1582-9.

145. Aron C, Moutaux G. [Non-invasive ventilation in acute or chronic respiratory failure: a comparison of volumetric ventilation]. Rev Mal Respir 1999;16:181-7. French.

146. Battisti A, Tassaux D, Bassin D, et al. Automatic adjustment of noninvasive pressure support with a bilevel home ventilator in patients with acute respiratory failure: a feasibility study. Intensive Care Med 2007;33:632-8.

147. Bellone A, Spagnolatti L, Massobrio M, et al. Short-term effects of expiration under positive pressure in patients with acute exacerbation of chronic obstructive pulmonary disease and mild acidosis requiring non-invasive positive pressure ventilation. Intensive Care Med 2002;28:581-5.

148. Fernández-Vivas M, Caturia-Such J, Gonzalez de la Rosa J, et al. Noninvasive pressure support versus proportional assist ventilation in acute respiratory failure. Intensive Care Med 2003;29:1126-33.

149. Gay PC, Hess DR, Hill NS. Noninvasive proportional assist ventilation for acute respiratory insufficiency. Am J Respir Crit Care Med 2001;164:1606-11. 
150. Girault C, Richard JC, Chevron V, et al. Comparative physiologic effects of noninvasive assist-control and pressure support ventilation in acute hypercapnic respiratory failure. Chest 1997 ; 111:1639-48.

151. Girault C, Chevron V, Richard JC, et al. Physiological effects and optimization of nasal assist-control ventilation for patients with chronic obstructive pulmonary disease in respiratory failure. Thorax 1997;52:690-6

152. International Consensus Conferences in Intensive Care Medicine: noninvasive positive pressure ventilation in acute respiratory failure. Am J Respir Crit Care Med 2001;163:283-91.

153. Consensus Conference IV: noninvasive positive pressure ventilation. Respir Care 1997:42:362-9.

154. British Thoracic Society. BTS guideline: noninvasive ventilation in acute respiratory failure. Thorax 2002;57:192-211.

155. Sinuff T, Keenan SP. Clinical practice guideline for the use of noninvasive positive pressure ventilation in COPD patients with acute respiratory failure. J Crit Care 2004;19:82-91.

156. Chawla R, Khilnani GC, Suri JC, et al. Guidelines for noninvasive ventilation in acute respiratory failure. Indian J Crit Care Med 2006;10:117-47.

157. Schönhofer B, Kuhlen R, Neumann P, et al. [Non-invasive ventilation as treatment for acute respiratory insufficiency. Essentials from the new S3 guidelines]. Anaesthesist 2008;57:1091-102. German.

158. GRADE Working Group. Grading quality of evidence and strength of recommendations. BMJ 2004:328:1-3

159. Schünemann HJ, Jaeschke R, Cook DJ, et al. An official ATS statement: grading the quality of evidence and strength of recommendations in ATS guidelines and recommendations. Am J Respir Crit Care Med 2006;174:605-14.

160. Guyatt G, Gutterman D, Baumann MH, et al. Grading strength of recommendations and quality of evidence in clinical guidelines: report for an American College of Chest Physician Task Force. Chest 2006;129:174-81.

161. Cluzeau FA, Littlejohns P, Grimshaw JM, et al. Development and application of a generic methodology to assess the quality of clinical guidelines. Int J Qual Health Care 1999;11:21-8.

162. Masip J, Roque M, Sanchez B, et al. Noninvasive ventilation in acute cardiogenic pulmonary edema: systematic review and meta-analysis. JAMA 2005;294:3124-30.

163. Peter JV, Moran JL, Phillips-Hughes J, et al. Effect of noninvasive positive pressure ventilation (NIPPV) on mortality in patients with acute cardiogenic pulmonary oedema: a metaanalysis. Lancet 2006;367:1155-63.

164. Winck JC, Azevedo LF, Costa-Pereira A, et al. Efficacy and safety of non-invasive ventilation in the treatment of acute cardiogenic pulmonary edema - a systematic review and metaanalysis. Crit Care 2006;10:R69.

165. Ho KM, Wong K. A comparison of continuous and bi-level positive airway pressure non-invasive ventilation in patients with acute cardiogenic pulmonary oedema: a meta-analysis. Crit Care 2006; 10:R49.

166. Collins SP, Mielnicznik LM, Whittingham HA, et al. The use of noninvasive ventilation in emergency department patients with acute cardiogenic pulmonary edema: a systematic review. Ann Emerg Med 2006;48:260-9.

167. Keenan SP, Henderson WR. Does non-invasive ventilation have a role in preventing intubation? In: Esquinas Rodriguez AM, editor. Yearbook of noninvasive mechanical ventilation. Sant Ano, Almeria (Spain): Fontomechanica Indalo; 2008. p. 149-54.

168. Nava S, Hill N. Non-invasive ventilation in acute respiratory failure. Lancet 2009;374:250-9.

169. Arozullah AM, Daley J, Henderson WG, et al. Multifactorial risk index for predicting postoperative respiratory failure in men after major noncardiac surgery. Ann Surg 2000;232:242-53.

170. Epstein SK, Faling LJ, Daly BDT, et al. Predicting complications after pulmonary resection. Preoperative exercise testing vs a multifactorial cardiopulmonary risk index. Chest 1993;104:694-700.

171. Sinuff T, Cook DJ, Giacomini M, et al. Facilitating clinician adherence to guidelines in the intensive care unit: a multicenter, qualitative study. Crit Care Med 2007;35:2083-9.

172. Sinuff T, Kahnamoui K, Cook DJ, et al. Practice guidelines as multipurpose tools: a qualitative study of noninvasive ventilation. Crit Care Med 2007;35:776-82.

173. Demoule A, Girou E, Richard J, et al. Increased use of noninvasive ventilation in French intensive care units. Intensive Care Med 2006;32:1747-55

174. Burns KE, Sinuff T, Adhikari NK, et al. Bilevel noninvasive pressure ventilation for acute respiratory failure: survey of Ontario practice. Crit Care Med 2005;33:1477-83.

Competing interests: Sean Keenan received an honorarium from Philips/Respironics Inc. to give a talk based on these guidelines. No competing interests declared by the other authors.
Members of the Canadian Critical Care Trials Group / Canadian Critical Care Society Noninvasive Ventilation Guidelines Group: Dr. Sean P. Keenan, Department of Critical Care Medicine, Royal Columbian Hospital, University of British Columbia, Vancouver, BC; Dr. Tasnim Sinuff, Department of Critical Care Medicine, Sunnybrook Health Sciences Centre, and Interdepartmental Division of Critical Care Medicine, University of Toronto, Toronto, Ont.; Dr. Karen E.A. Burns, Interdepartmental Division of Critical Care Medicine, the Keenan Research Centre and the Li Ka Shing Knowledge Institute, St. Michael's Hospital, Toronto, Ont.; Dr. John Muscedere, Department of Medicine, Queen's University and Kingston General Hospital, Kingston, Ont.; Dr. Jim Kutsogiannis, Division of Critical Care Medicine, University of Alberta, Edmonton, Alta.; Dr. Sangeeta Mehta, Department of Medicine and the Interdepartmental Division of Critical Care Medicine, Mount Sinai Hospital, University of Toronto, Toronto, Ont.; Dr. Deborah J. Cook, Department of Medicine, McMaster University, Hamilton, Ont.; Dr. Najib Ayas, Department of Medicine, University of British Columbia, Vancouver, BC; Dr. Neill K.J. Adhikari, Interdepartmental Division of Critical Care Medicine, University of Toronto, and the Sunnybrook Research Institute, Toronto, Ont.; Lori Hand, Department of Clinical Epidemiology and Biostatistics, McMaster University, Hamilton, Ont.; Dr. Damon C. Scales, Interdepartmental Division of Critical Care Medicine, University of Toronto, and the Sunnybrook Research Institute, Toronto, Ont.; Rose Pagnotta, Department of Respiratory Therapy, Royal Inland Hospital, Kamloops, BC; Lynda Lazosky, Division of Critical Care Medicine, St. Paul's Hospital, Vancouver, BC; Dr. Graeme Rocker, Division of Respirology, Queen Elizabeth II Health Sciences Centre and Dalhousie University, Halifax, NS; Dr. Sandra Dial, Critical Care Medicine, Sir Mortimer B. Davis Jewish General Hospital, and the Respiratory Epidemiology and Clinical Research Unit, Montreal Chest Institute, McGill University, Montréal, Que.; Dr. Kevin Laupland, Department of Critical Care Medicine, University of Calgary, Calgary, Alta; Dr. Kevin Sanders, Department of Medicine, North York Hospital, Toronto, Ont.; and Dr. Peter Dodek, Division of Critical Care Medicine, Department of Medicine, St. Paul's Hospital and University of British Columbia, Vancouver, $\mathrm{BC}$

Contributors: Sean Keenan and Tasnim Sinuff are joint first authors on this paper. They led the process of guideline development, performing initial and subsequent selection of trials for review, coordinating distribution of material for review and face-to-face meetings and leading manuscript writing and submission. All of the authors were involved in the perception and design of the guideline development project and took part in a review of the GRADE process of guideline development before meetings. All of the authors except for Deborah Cook and Peter Dodek were involved in reviewing and evaluating selected trials and presenting summaries of these trials at the meetings. All authors were involved in discussions of the literature presented and in drafting initial statements following the GRADE process during the meetings. All of the authors contributed to the writing and revising of the manuscript and approved the final version submitted for publication.

Funding: This work was funded by a grant from the Canadian Institutes of Health Research (CIHR) and an unrestricted grant from Philips/Respironics Inc., Murrysville, Pa. Neither funding body was involved in any stage of the development of the guidelines or the preparation of the manuscript.

Tasnim Sinuff and Karen Burns are supported by a CIHR Research Clinician Scientist Award. Deborah Cook is a Canada Research Chair of the CIHR. Damon Scales has received a CIHR New Investigator Award

Acknowledgements: The authors are grateful to Roman Jaeschke for his advice regarding GRADE methodology and to Dr. Stefano Nava for his input. They thank the Canadian Critical Care Trials Group and the Canadian Critical Care Society for their support in developing this guideline. 